IZA DP No. 6520

The Impact of Early Life Economic Conditions on Cause-Specific Mortality During Adulthood

Gary Y.C. Yeung

Gerard J. van den Berg

Maarten Lindeboom

France R.M. Portrait

April 2012 


\title{
The Impact of Early Life Economic Conditions on Cause-Specific Mortality During Adulthood
}

\author{
Gary Y.C. Yeung \\ VU University Amsterdam \\ Gerard J. van den Berg
University of Mannheim, IFAU,
VU University Amsterdam and IZA \\ Maarten Lindeboom \\ VU University Amsterdam, HEB, \\ Tinbergen Institute, Netspar and IZA
}

France R.M. Portrait

VU University Amsterdam

Discussion Paper No. 6520

April 2012

IZA

P.O. Box 7240

53072 Bonn

Germany

Phone: +49-228-3894-0

Fax: +49-228-3894-180

E-mail: iza@iza.org

Any opinions expressed here are those of the author(s) and not those of IZA. Research published in this series may include views on policy, but the institute itself takes no institutional policy positions.

The Institute for the Study of Labor (IZA) in Bonn is a local and virtual international research center and a place of communication between science, politics and business. IZA is an independent nonprofit organization supported by Deutsche Post Foundation. The center is associated with the University of Bonn and offers a stimulating research environment through its international network, workshops and conferences, data service, project support, research visits and doctoral program. IZA engages in (i) original and internationally competitive research in all fields of labor economics, (ii) development of policy concepts, and (iii) dissemination of research results and concepts to the interested public.

IZA Discussion Papers often represent preliminary work and are circulated to encourage discussion. Citation of such a paper should account for its provisional character. A revised version may be available directly from the author. 


\section{ABSTRACT \\ The Impact of Early Life Economic Conditions on Cause-Specific Mortality During Adulthood}

The aim of this study is to assess the effects of economic conditions in early life on causespecific mortality during adulthood. The analyses are performed on a unique historical sample of 14,520 Dutch individuals born in 1880-1918, who are followed throughout life. The economic conditions in early life are characterized using cyclical variations in annual real per capital Gross Domestic Product during pregnancy and the first year of life. Exposure to recessions during pregnancy and/or the first year of life appears to significantly increase allcause mortality risks and cancer mortality risks of older males and females. It also significantly increases mortality risks due to cardiovascular diseases and chronic respiratory diseases of older females. The residual life expectancies are up to 4.5 to $8 \%$ lower for allcause mortality and up to 1.5 to $7.8 \%$ lower for cause-specific mortality. Our analyses show that cardiovascular and cancer mortality risks are related and that not taking this association into account leads to biased inference.

JEL Classification: I12, C41

Keywords: life expectancy, cancer, cardiovascular disease, survival analyses, competing mortality risks, recession

Corresponding author:

France R.M. Portrait

Institute of Health Sciences

VU University Amsterdam

de Boelelaan 1085

1081 HV Amsterdam

The Netherlands

E-mail: france.portrait@falw.vu.nl

\footnotetext{
*Acknowledgements: We thank participants at the European Social Science History Conference, the International Student Congress of Medical Sciences, and the European Conference on Health Economics for their useful suggestions. This project was part of the first author's extracurricular research program of medicine at the VU University Amsterdam. We thank Henk de Vries and the referees of that program for their useful comments.

Data acknowledgements: We are indebted to the International Institute of Social History in Amsterdam (IISH), Statistics Netherlands in The Hague (CBS) and Angus Maddison, for access to their data. We thank CBS Centre for Policy Related Statistics in The Hague for their assistance and Kees Mandemakers (IISH) for his help during the project.

Financial acknowledgement: This project received financial support from the VU University Medical Centre's department of general practice in Amsterdam, for the acquisition of the CBS data.
} 


\section{INTRODUCTION}

Early life socioeconomic conditions may partly explain mortality outcomes at older ages. For instance, the recent review of Galobardes, Lynch \& Davey-Smith (2008) demonstrates that adverse childhood socioeconomic conditions are positively related with increased mortality risks in later life, due to e.g. (stomach) cancer, hemorrhagic stroke, coronary heart disease and chronic obstructive pulmonary disease (COPD).

From a public health policy perspective, understanding the mechanisms linking early life (economic) conditions and survival is important as it may help the design of successful strategies to prevent premature death and reduce (socio-economic) differentials in mortality. However, there are substantial methodological challenges in identifying causal effects of early life (economic) conditions on (cause-specific) mortality at older ages. Most importantly, a source of exogenous variation is needed that affects the early life (economic) conditions but that is not confounded by individual characteristics and that does not have additional effects on late-life health other than the effect running through early-life conditions. A recent branch of the literature uses exogenous variation due to fluctuations in contextual conditions, notably epidemics (e.g. Bengtsson \& Lindstrom, 2003; Almond, 2006), famines (e.g. Chen \& Zou, 2007; Lindeboom, van den Berg, Portrait, 2010) and business cycles (van den Berg, Lindeboom \& Portrait, 2006), to identify causal links. Van den Berg, Lindeboom \& Portrait (2006) show that birth in a recession during the nineteenth century in the Netherlands resulted on average in an $8 \%$ increase in the all-cause mortality rate. The study of van den Berg, Doblhammer \& Christensen (2011) also demonstrates increased mortality rates after exposure to recession at birth in a Danish population of twins born in 1873-1906. The same study provides evidence of higher cardiovascular mortality risks at older ages after exposure to a lower real GDP per capita at birth, but shows no increased cancer mortality risks. 
The present research explores further the relationships between economic conditions in early life and mortality in later life using business cycles as a source of exogenous variation. We elaborate on the previous literature in three main distinctive ways. First, the study focuses on a large number of major death risks, namely all-cause mortality, and mortality due to cancer, cardiovascular diseases, chronic respiratory diseases, cognitive diseases, external causes and other causes. Those death risks have all been shown (except for external causes and other causes) to be associated with conditions in early life (Kuh \& BenShlomo 2004).

To explain the second contribution of our paper, notice that studies on cause-specific mortality, whether they focus on early-life conditions or not, typically only focus on one specific mortality risk or assume that the processes underlying several cause-specific mortality risks are not related (after controlling for observed characteristics), so that inference on cause-specific mortality can treat death due to other causes as independent right-censoring of the outcome of interest. Clearly, ignoring dependence may lead to incorrect results. A few studies address dependence (without addressing early-life conditions). Wienke et al. (2002) allow competing mortality risks to be related through unobserved heterogeneity terms. They estimate models with and without conditional independence, using data on Danish twins. They conclude that mortality from coronary heart diseases and mortality from other causes are conditionally independent. Honoré \& Lleras-Muney (2006) perform nonparametric analyses and conclude that cardiovascular mortality and cancer mortality are related and that the declines in cancer mortality in the past decades are much larger when taking into account the improvements in cardiovascular mortality. In the present paper we estimate models allowing for dependent risks of cardiovascular and cancer mortality through unobserved heterogeneity. Cardiovascular diseases and cancer have become major health problems worldwide and account currently for over $50 \%$ of all deaths in both developed and developing countries 
(Yusuf et al., 2001). In addition, cancer and cardiovascular diseases are known to have common risk factors like certain types of lifestyles or education, which may not be completely controlled for by observed covariates (W.H.O., 2005).

Third, the analyses in this paper are performed on a large representative sample from a national population, consisting of 14,520 Dutch individuals born in 1880-1918, who are followed through life or until December $31^{\text {st }}$, 2005. The above-mentioned study of Van den Berg, Doblhammer and Christensen (2011) uses Danish twin data, which enables them to compare monozygotic to dizygotic twins and to address whether the dependence between outcomes of a twin pair is stronger after birth in a recession. However, a twin birth poses a heavier burden on the household than the birth of a single child, suggesting that exogenous variation in early-life conditions will be expressed more strongly through twins. This makes it important to investigate whether effects on cause-specific mortality rates are also present in data on singletons.

The rest of the paper is structured as follows. Section 2 presents the data. Section 3 describes our estimation strategy, dealing successively with the non-parametric and parametric analyses. The results are presented in section 4. All analyses are performed by gender, as there is evidence in the literature that the mechanisms linking early life conditions and old age mortality differ across gender (see below). The results are discussed in detail in section 5 .

\section{DATA}

\section{Main dataset and sample}

Our main data come from the Historical Sample of the Netherlands Data Set Life Courses (Release 2008.01) (HSN). The HSN gathers lifetime information on a random sample of 
approximately 80,000 Dutch individuals born in the period 1812-1922. Currently, the end of the observation window is December $31^{\text {st }}$, 2005. The HSN data have been collected from certificates of birth, marriage, and death. The HSN dataset follows individuals who migrated within the country, in order to limit loss to follow-up. Note that relatively few Dutch individuals migrated abroad at that time, compared to for example Germany, Scotland, and Ireland (Wintle, 2000). Most importantly for this study, the HSN data include the exact date of birth and date of death, gender, place of birth, and several family characteristics at birth such as occupations of the parents, marital status of the mother and literacy of the father. See Mandemakers (2000) for an extensive description of the HSN data.

The date of death of individuals born in the most recent cohorts is often missing. We do not know whether the individuals with unknown date of death are still alive or whether the information is missing. Therefore, we have decided to exclude from the analyses the birthcohorts 1919-1922 (n=2,053). For reasons of availability of data on causes of death and to keep the heterogeneity of the sample within limits, the empirical analyses are based on the HSN cohorts born in the period 1880-1918 (see next paragraph for more details). This amounts to a total of 25,455 HSN individuals. Information on causes of death is only available for individuals who died after 1937. Exclusion of the individuals who died before 1937 results in a sample of 15,316 HSN individuals. Obviously, we need to control for this selection in the estimation strategy. After exclusion of the individuals with missing information on the included covariates (see next paragraph “Additional variables”), we end up with a sample of 14,520 individuals. 


\section{Outcomes: All-cause and cause-specific mortality}

Lengths of life are calculated using exact dates of birth and dates of death ${ }^{1}$ and are therefore exactly observed in number of days. The HSN data do not include information on causes of death. We solve this drawback by merging the HSN data with official data on causes of deaths from Statistics Netherlands (CBS). CBS registers the primary and secondary causes of death of all individuals who have died in the Netherlands since January $1^{\text {st }}, 1937$. Only the primary cause of death, which describes the originating cause of death, is used in the present study. The secondary causes of death are diseases which are a consequence of the primary cause of death or other diseases present at time of death and which may also have contributed to death.

CBS uses the International Classification of Diseases (ICD) version used at the time of death to code the causes of death. In total, ICD-4 to ICD-10 were used in the period 19372005 to classify the causes of death. Janssen \& Kunst (2004) provide a concordance table to bridge versions 6 to 10 of the ICD for 26 important causes of death at old ages in the Netherlands. We have used ICD books 4 and 5 to bridge versions 4 to 6 (CBS 1935, CBS 1940). The resulting concordance table used in our empirical analyses to classify the diseases along the full observation window is shown in Table 1.

$<$ Here Table $1>$

The coding of diseases may be affected by the use of different versions of International Classification of Diseases (ICD) over time (Janssen \& Kunst 2004). Each revision of the ICD led to discontinuities that are partly caused by developments in medical

\footnotetext{
${ }^{1} 3.8 \%$ of the HSN individuals have no recorded day of death. In this case, the date of death was set on the $15^{\text {th }}$ of the month of death. On the other hand, $3.7 \%$ of the HSN individuals have a registered year of death but no month and day of death. We have solved this missing data problem by setting their actual date of death at July, $1^{\text {st }}$. Note that the results remain to a large extent similar if we exclude these individuals from the analyses.
} 
science and partly by changes in disease concepts (Janssen \& Kunst 2004). However, recent research shows that the coding of important causes of death (such as cancer or cardiovascular diseases) by Statistics Netherlands is highly reliable (e.g. intercoder agreement equals about 85\% and intracoder agreement equals about 90\%) (Harteloh et al. 2010).

In the main empirical analyses, all types of cancer are grouped into one category. Our category "Cardiovascular diseases” (CVD) includes ischemic heart diseases, cerebrovascular diseases and other heart or circulatory diseases. The category "Chronic respiratory diseases" includes chronic obstructive pulmonary diseases (COPD) and asthma. The category “Cognitive diseases” includes all types of dementia. External causes of death include (traffic) accidents, homicide, suicide and poisoning. The category “Other causes of death" groups the remaining natural causes of diseases that are not included in the above categories. The different categories of causes of death are mutually exclusive.

Figure 1 shows the distribution of the availability of the causes of death of the HSN cohorts 1863-1918 by birth year. The earliest birth cohorts had to survive the longest to have a registered cause of death. As expected, Figure 1 shows the highest percentages of individuals without a cause of death for the earliest cohorts. Note that a relative large share of individuals has a registered cause of death from birth-cohort 1880 onwards. All this motivates why only the birth-cohorts 1880-1918 are used in the empirical analyses. Our selection is also motivated by historical considerations, since the Netherlands underwent, from 1870 onwards, big changes and went from a rather poor mainly agrarian society to an industrial and modern society (Wintle, 2000). We return to this in the paragraph "Main determinant: Economic conditions in early life”.

$39.8 \%$ of the sample participants have no information after birth, or they died before $1 / 1 / 1937$, or they are censored at a date before $1 / 1 / 1937$. These individuals are excluded from the analyses. Note that this group has on average the same characteristics at birth than the 
other sample members. $6 \%$ of the HSN individuals born in 1880-1918 who have survived at least until January $1^{\text {st }}$, 1937, have no date of death. Their lifetime is right-censored at the last date of observation, for instance at a last recorded date of marriage or birth of a child. CBS was able to retrieve a cause of death for $98 \%$ of the 13,773 HSN individuals born in 1880 1918 and who have a registered date of death after January $1^{\text {st }}$, 1937 . The percentage of missing causes of death is somewhat higher for individuals who died just after 1937 and declines to about $1.5 \%$ at the end of the forties and remained approximately constant until 2006. There is one major exception: the percentage of missing causes of death at the end of World War II in 1945 equals 39\%. According to CBS, the missing data are a consequence of missing information in the earliest registers of CBS, the occurrence of World War II and differences in the death certificate numbers in the HSN and CBS data.

$<$ Here Figure $1>$

Table 2 presents the prevalence by gender and by birth cohort in our sample of the seven primary causes of death included in the study. Cardiovascular diseases (41.3\%) are the most prevalent primary cause of death followed by cancer (21.4\%) for both males and females.

$<$ Here Table 2>

\section{Main determinant: Economic conditions in early life}

The HSN data are merged with Dutch macroeconomic data in order to characterize the early life economic environment of the HSN individuals. We have opted for the annual real Gross Domestic Product (GDP) per capita (Maddison 2009) mostly for reasons of availability of consistent data over the full observation window. Figure 2 shows the annual real GDP in 
the period 1880-1922 as well as the GDP trend calculated using the Hodrick-Prescott methods (see paragraph below).

$<$ Here Figure 2 $>$

Figure 2 shows that the annual real GDP increased across the full observation window, reflecting the improvement of the living standards in the Netherlands at that time. Around 1870, the public health facilities underwent big changes in the Netherlands, such as the introduction of a public vaccination campaign, clean water supply and improved care for the poor. All this resulted in reduced death rates in the following years and higher life expectancy for newborns (Wintle 2000, van Poppel et al. 2005). These secular improvements make it difficult to compare lifetimes of individuals born during different periods of good and bad times. Therefore the GDP series is decomposed using the Hodrick-Prescott filter, with smoothing parameter set on $500,{ }^{2}$ into a non-stationary trend and a cyclical component (Hodrick and Prescott 1997).

The observed cycles are consistent with the historically documented economic fluctuations. For example, the severe economic depression in 1918 is also observed in the decomposed series. Three expansions are observed in our data: around 1885, and before and after World War I. In the years prior to World War I, the economies in most European countries experienced economic expansion, including the Dutch economy (Moeyes 2001). Although the Netherlands remain neutral during World War I, its economy was dependent on international trade and the (foreign) demand decreased substantially due to both the war and the pandemic. The GDP dropped by almost 20 percent between 1913 en 1918 (van Zanden

\footnotetext{
2 The results were very similar with smoothing parameter equal to 100 . There was one exception: the decomposition based on smoothing parameter equal to 100 showed an economic boom at the beginning of World War I, which is not documented in historical literature (see next paragraph).
} 
1998). At the end of World War I, the Dutch government encouraged Dutch companies to invest in Germany. The Germans were rebuilding their economy and most European countries were not eager to help the former aggressor, except the Netherlands. Exports increased in the years 1923-1929 with 6.8\% each year and consumption increased almost 3\% each year (van Zanden 1998).

The cyclical components are our main indicator of the economic situation in early life. A positive (respectively negative) deviation is interpreted as an economic expansion (respectively recession). Since only information on annual GDP is available, the individual cyclical indicators during pregnancy or first year of life are calculated as a weighted average of the annual deviations based on their month of birth. This is to better reflect the state of the business cycle during pregnancy and first year of life. For instance, the cyclical indicator in the first year of life of an individual born in December equals 1/12 of the cyclical value at year of birth and 11/12 of the GDP cyclical value in the year following year of birth. Note that this correction assumes that individuals are all born on the first of the month and that all pregnancies have lasted nine months. The effects of the cyclical movements are not dominated by the secular improvements at an individual level, and these cyclical changes can result in unexpected income shocks and changes of consumption pattern of the HSN individuals (Vugs 2002, van den Berg et al. 2006).

\section{Additional variables}

Geographical location The HSN data record the province and the municipality of birth. We classify the municipalities of birth into urban or rural area based on the information available on the population density of municipalities in the 1889 census of the Netherlands (CBS). We construct a binary indicator defined as following: a municipality is defined as rural, if the density is lower than twenty thousand residents per thousand hectare land. 
Parental occupation The occupation of the father at birth is used as a proxy for the socioeconomic status at birth of the HSN participant. ${ }^{3}$ The HSN data include the profession of the birth informer mentioned on the birth certificate of the HSN individuals. The father was the birth informer for $94.8 \%$ of the HSN individuals. We replace the missing code by a score equal to zero for individuals for which the birth informer was not the father and include in the empirical analyses a dummy variable that indicates whether the father was the informer or not. This is to avoid excluding from the empirical analyses the individuals for which the father was not the birth informer. HSN coded all occupations using the 5-digit coding scheme Historical International Standard Classification of Occupations (HISCO) developed by Van Leeuwen et al. (2002). These codes were in turn classified into socioeconomic classes using the HISCLASS-scheme developed by Van Leeuwen and Maas (2005). The HISCLASS classification consists of twelve social classes and each class clusters professions together with roughly the same workload, skill level and within the same economic sector. Van Leeuwen and Maas (2005) developed also an alternative version of HISCLASS consisting of seven classes to avoid small numbers in some classes. We use this abridged version in the empirical analyses.

Literacy HSN uses the presence of a signature on the birth certificate as an indication of the literacy of the birth informer. The father is considered as literate (respectively, illiterate) if the father was the birth informer and he had (respectively, had not) signed the register. We use the same technique as described in the previous paragraph to avoid excluding individuals where the father was not the birth informer.

\footnotetext{
${ }^{3}$ Note that parental socioeconomic status during childhood may be endogenous, as other factors such as parental lifestyle may both affect socioeconomic position of the parents and health of the HSN participant.
} 
Marital status of the mother Three dummies are used to characterize the marital status of the mother at birth of the HSN individuals indicating whether the mother was married, unmarried or whether the marital status was unknown.

Table 3 provides descriptive sample statistics on the included variables. Almost all mothers are married (99\%), and almost all fathers are the birth informer (97\%) and are literate (93\%). As expected, most fathers belong to the manual classes (79\%). The individuals in our sample are born all over the Netherlands and most of them are born in a rural environment (72\%).

$<$ Here Table 3>

\section{STATISTICAL ANALYSES}

We perform non-parametric and parametric analyses. We stratify our sample by gender since the results in the relevant empirical literature are often gender-specific (Koupil et al. 2007). Moreover, literature suggests that female adult health is more likely to be influenced by childhood conditions than male adult health (Luo \& Waite 2005, Hamil-Luker and O'Rand 2007, Chapman 2009). This could be caused by biological differences between males and females adapting differently to early life events or by the different types of roles males and females have in society. Males seem also to have more opportunities and means to counter early life events during adulthood than females (Hamil-Luker and O'Rand 2007).

\section{Non-parametric analyses}

First, following the approach in van den Berg, Doblhammer \& Christensen (2011), we decompose the time series on residual life expectancy at age 57 using Hodrick-Prescott methods with smoothing parameter 500, into a non-stationary trend and a cyclical component 
(Hodrick \& Prescott 1997). ${ }^{4}$ The deviation to the trend in residual life expectancy is measured in $10^{-4}$ days, so that a deviation of 0.018 from the trend corresponds to 180 days (=6 months). We draw a figure that displays on the x-as the GDP cyclical component at each calendar year and, on the y-as, the annual deviations in residual life expectancy at age 57 . This allows us to investigate whether the two series are correlated with each other.

Second, we draw Kaplan Meier survival curves for all-cause mortality and for mortality due to cancer, cardiovascular diseases, chronic respiratory diseases, and cognitive disease by gender. Recall from the paragraph "Main determinant: Economic conditions in early life" that, due to secular improvements over time, we cannot easily compare the survival of individuals born in economic upturns with the one of individuals born in recessions. Therefore we compare the survival curves of two subsequent birth cohorts: the first cohort is born in 1910-13 and is exposed to an expansion at birth and the second cohort is born in 1914-18 and is exposed to a recession at birth. Note that the results cannot be explained by any increasing secular trend since the improvements work at the advantage of those born later, namely those born during the recession. Therefore, significant favourable effects on mortality during adulthood for those born during the economic expansion (1910-13) will underestimate the true effects. Recall that the Dutch population did not experience severe war conditions during World War I (1914-1918).

\section{Parametric analyses}

Extended Cox models In our first set of analyses, we analyse the impact of economic conditions in early life on all-cause mortality. We estimate extended Cox models ${ }^{5}$ that

\footnotetext{
${ }^{4}$ Individuals born in 1880 had to survive at least 57 years to have a registered cause of death (available from 1937).

${ }^{5}$ Extended Cox models are equivalent to Cox models that are extended to allow for time dependent variables (Kleinbaum \& Klein, 2005).
} 
account for the long-term effects of early life economic conditions, for the contemporaneous effects of World War II (using a dummy variable taking the value “1” for calendar years 1940-45, and "0" otherwise) and for the contemporaneous effect of other time-varying macro conditions that may influence individual mortality rates. Concerning the latter, we use a flexible characterisation of calendar time (using Chebyshev polynomials of degree 3, see for more information e.g. Lowan, 1972). The models are also corrected for the individual variables that are described in the paragraph “Additional variables” above. Per model, we characterize the early life economic conditions in four different ways. Specification 1 only corrects for GDP variations during pregnancy. Specification 2 corrects for GDP variations during the first year of life. Specification 3 includes both previous variables. Variations in GDP during pregnancy and during the first year of life year may be highly correlated, which may bias the coefficients of the early life economic determinants in Specification 3. Therefore we also estimate a specification that includes the average cyclical GDP component during pregnancy and first year of life (Specification 4). Finally, remember that Statistics Netherlands have gathered information on causes of death since January $1^{\text {st }}$, 1937 . Therefore we adjust all our parametric analyses for survival until that date.

In the following, Competing Risk Models (CRM) are used to estimate cause-specific mortality risks by gender. CRM are highly appropriate in the context of this study to account for the fact that individuals are simultaneously exposed to several, competing, mortality risks.

Independent Competing Risk Models In our second set of analyses, we assume that the risks for different causes of death are independent of each other, after controlling for observed characteristics. It is easy to show that the assumption of independent risks boils down to estimating conventional survival models for each cause of death $k$, where the durations to other causes of death are considered as censored at the moment of death (i.e. meaning that the event "other cause of death" has not yet occurred until the timing of death) 
(see, for example, Cameron \& Trivedi, 2005). We estimate the independent CRM for the various causes of death considered in the study. We again characterize each mortality risk using extended Cox models. Each model includes the same explanatory variables as the ones described in the previous paragraph.

Dependent Competing Risk Models Mixed Proportional Hazard Models are used to characterize the mortality risks. Theoretically we could jointly model all causes of death considered in this paper. However, here we reach the limit of what is feasible in our study. In the empirical analyses, we assume that the two broad disease categories "Cancer" and “Cardiovascular diseases” are affected by common unobserved factors and that other causes of death are independent of each other. Recall that the latter mortality risks are most important as they currently account for over $50 \%$ of all deaths in both developed and developing countries (Yusuf et al., 2001). Moreover, Honoré \& Lleras-Muney (2006) also find strong correlations between those two risks, and conclude that not taking this correlation into account can lead to incorrect conclusions. As shown in the previous paragraph, the likelihood function factorizes then into six parts, of which the two dependent risks are one and the remaining five death risks are five. Each sub-likelihood function can be optimized independently. From now on, we focus on the death risks "Cancer" and "Cardiovascular diseases".

The hazard function $\theta_{k}$ associated with cause of death $k$ is given by (for reasons of clarity, we abstain from using the individual index i):

$$
\theta_{k}\left(t / X, v_{k}\right)=\lambda_{k}(t) \cdot \phi(x, z(\tau)) \cdot V_{k}, \quad k \in(c, c v d)
$$

where $t$ refers to age, $X$ refers to a set of exogenous variables and $V_{k}$ refers to the unobserved heterogeneity component of cause of death $k, \lambda_{k}(t)$ denotes the baseline hazard, 
which is the same for all individuals but varies across the causes of death $k, c$ refers to cancer and $c v d$ to cardiovascular diseases. The baseline hazard is characterized using a Gompertz function defined by: $\lambda_{k}(t)=e^{\alpha_{k} t}$. This is for the following reason: we retrieved estimates of the baseline hazard after estimation of the previous extended Cox models, and these estimates indicated that the Gompertz function was sufficiently flexible to model the relationship from age 22 and above (all HSN individuals are at least 22 years old in 1937). The regressor function $\phi(x, z(\tau))$ depends on a set of observed time-constant individual characteristics $x$ and time-varying macro conditions $z$ dependent on calendar time $\tau$. The regressor function $\phi(x, z(\tau))$ includes the same observed characteristics as described in the previous paragraphs. We opt for a flexible bivariate discrete mass-point distribution to characterize the unobserved heterogeneity distribution:

$$
P\left(V_{c}=v_{c}^{m}, V_{c v d}=v_{c v d}^{n}\right)=p_{m n}
$$

where $v_{c}^{m}, v_{c v d}^{n}$ for $m=1, . ., M$ and $n=1, . ., N$ are the mass points to be estimated and $p_{m n} \geq 0, \sum_{m, n} p_{m n}=1$

Using the same notation as before, conditional on the unobservables $V_{k}, k=c, c v d$, the individual (i) contribution to the likelihood function is given by:

$$
\begin{aligned}
& L_{i}\left(\beta_{c}, \beta_{c v d} \mid V_{c}, V_{c v d}\right)=\theta_{c}\left(t \mid x, z(\tau), V_{c}\right)^{d_{c}} \theta_{c v d}\left(t \mid x, z(\tau), V_{c v d}\right)^{d_{c v d}} \\
& \exp \left(-\int_{t_{1 / 1 / 1937}}^{t}\left[\theta_{c}\left(s \mid x, z(\tau), V_{c}\right)+\theta_{c v d}\left(s \mid x, z(\tau), V_{c v d}\right)\right] d s\right)
\end{aligned}
$$

where $\beta_{k}$ is the set of parameters to be estimated for each death risk $k, d_{k}=1$, if an individual is observed to die of cause $k$, and 0 otherwise. Note that we adjust the likelihood function for survival until January $1^{\text {st }}, 1937$ as the causes of death are only available from 
January $1^{\text {st }}$, 1937 (i.e. $t_{1 / 1 / 1937}$ refers to age at January $\left.1^{\text {st }}, 1937\right)$. Recall that $V_{c}$ and $V_{c v d}$ follow a bivariate discrete distribution (2) and it follows that when $V_{c}$ and $V_{c v d}$ are correlated so are the cancer and cardiovascular death risks. The individual contribution to the unconditional likelihood function is given by:

$$
\begin{aligned}
& L_{i}\left(\beta, v_{c}, v_{c v d}, p\right)=\sum_{m, n}^{M, N} p_{m n} \theta_{c}\left(t \mid x, z(\tau), v_{c}^{m}\right)^{d_{c}} \theta_{c v d}\left(t \mid x, z(\tau), v_{c v d}^{n}\right)^{d_{c v d}} \\
& \exp \left(-\int_{t_{1 / 1 / 1937}}^{t}\left[\theta_{c}\left(s \mid x, z(\tau), v_{c}^{m i}\right)+\theta_{c v d}\left(s \mid x, z(\tau), v_{c v d}^{n}\right)\right] d s\right)
\end{aligned}
$$

where $\beta, v$ and $p$ are vectors, $m=1, \ldots, M$ and $n=1, . ., N$

To conclude, it is important to mention that the dependent Mixed Proportional Hazard competing risks model is identified (see e.g. Abbring \& van den Berg, 2003).

Residual life expectancies To quantify the impact of the early life economic conditions on the mortality risks, we also calculate using our model estimates the residual life expectancies at age 60 of males and females (1) exposed to an average economic recession, (2) exposed to the recession of 1918 (the most extreme recession in 1880-1918), and (3) exposed to neither a recession nor an expansion. We calculate the residual life expectancies at age $60 L E(60)$ as follows:

$$
L E(60)=\frac{\int_{s=60}^{\infty} S(s) d s}{S(60)}
$$

where $S(t)$ is the survival function. We perform the calculations for individuals born in 1918 with sample average characteristics, namely having married parents of a lower socioeconomic class, with a father who was literate and living in a rural environment of a 
province located in the South of the Netherlands. The conclusions remain qualitatively the same if we use different individual characteristics.

\section{RESULTS}

\section{Non parametric results}

Figure 3 displays the annual deviations in residual life expectancy at age 57 and the GDP cyclic components at each calendar year. The figure suggests a positive association between the two time series, and, indeed, the estimated correlation equals 0.425 (95\%CI: $0.13,0.66)$.

$<$ Here Figure 3>

Figures 4 and 5 show the Kaplan Meier survival curves of all-cause mortality and of mortality due to cancer, cardiovascular diseases, chronic respiratory diseases, and cognitive diseases for males and females, respectively. Recall that we compare the survival curves of individuals born in 1910-13 during an economic expansion (mean value of the GDP-cycle equal to 0.034 ) to the survival curves of individuals born in 1914-1918 during a recession (mean value of the GDP-cycle equal to -0.073). The graphs indicate an overall advantage in survival for both genders born in period of expansion compared to those born during the recession for the causes listed here, especially at older ages. Note that the graphical results are more convincing for females. However, the differences are not statistically significant. Finally, as expected, we find no differences in survival for external causes of death (results not shown here).

$<$ Here Figures 4 \& 5 > 


\section{Parametric results}

Extended Cox models for all-cause mortality Table 4 reports estimation results of extended Cox models for all-cause mortality for four different specifications of the early life economic conditions (see section 3 for more detail). ${ }^{6}$ The results show that experiencing a recession during pregnancy and/ or in the first year of life leads to significantly higher mortality rates later in life for both genders. The effects are larger for females. The coefficients of the other included explanatory variables have the expected signs but they are not always significant at conventional statistical levels.

Table 5 reports the residual life expectancies at age 60 for a male and a female born in 1918 with average individual characteristics (see paragraph "residual life expectancies" above). The results show that a male loses about $5 \%$ of his residual life expectancy at age 60 when he is born in a severe economic recession. This percentage equals about $7.5 \%$ for a female. Note that the figures are in accordance with official data on (residual) life expectancies. The life expectancy at birth of a male (respectively female) born during period 1916-1921 equals about 53.4 (55.3, respectively) and the residual life expectancy at age 60.5 equals 16.9 (21.7, respectively) (CBS StatLine 2009).

$<$ Here Tables 4 and $5>$

Independent Competing Risk Models Tables 6 and 7 report the estimation results of the independent CRM for the six causes of death under study for males and females, respectively. Again we estimate the models using four different specifications of the early life conditions.

\footnotetext{
${ }^{6}$ Specification 1 only corrects for GDP variations during pregnancy. Specification 2 corrects for GDP variations during the first year of life. Specification 3 includes both previous variables. Specification 4 includes the average cyclical GDP component during pregnancy and first year of life.
} 
$<$ Here Tables 6 and $7>$

Exposure to a recession during pregnancy for males and during the first year of life for females increases the risk of dying from cancer. The odd ratios comparing an average recession to an average expansion are statistically significant and equal 1.08 (95\%CI: 1.00, 1.15) for males exposed during pregnancy and 1.11 (95\%CI: 1.02, 1.20) for females exposed during first year of life. In addition, being exposed to a recession during the first year of life affects the risk of dying from chronic respiratory diseases of females. Mortality due to cardiovascular diseases is also higher among women born during a recession (results are only statistically significant at a $10 \%$ level). Furthermore, we find no statistically significant relationships for cognitive diseases and external causes of death (e.g. poisoning, traffic accidents, or homicides), except in Specification 3 where borderline statistically significance is reached. Finally, being exposed to recession increases significantly the risk of dying from “other causes” for females. The coefficients in Specification 3 greatly differ from the ones in Specifications 1, 2 and 4. This may be due to the fact that variations in GDP during pregnancy and during the first year of life are highly correlated (see section "Extended Cox Models"). It is maybe here even more prominent because of low numbers of treated individuals in each disease category. The coefficients of the other included explanatory variables have again the expected signs but are not always significant at conventional statistical levels. Figure 6 displays contemporaneous effects of calendar time. The figure indicates that the instant hazards of dying of cancer are lower than those of cardiovascular mortality, notably for males.

$<$ Here Figure $6>$

Dependent Competing Risk Models The models presented in this section allow for dependence between mortality risks due to cancer and cardiovascular diseases by means of unobserved individual heterogeneity. Table 8 reports the estimation results for males and 
females. For reasons of parsimony, we only report the results of specifications 1 and 2 (i.e. corrected for GDP during pregnancy and for GDP during first year of life, respectively) of the fully-adjusted models (i.e. models that are corrected for all covariates described in section 2). Note furthermore that, in our empirical applications, we take $M=2$ and $N=2$ though we have also tested in subsequent models whether more mass points needed to be added. However, these models failed to converge and suggested the existence of two discrete masspoints.

$<$ Here Table $8>$

The results of the dependent CRM confirm to a large extent those of the independent CRM for both genders. A major difference is that being exposed to recessions in early life appears in the dependent CRM to significantly increase the risks of cardiovascular mortality of females. For females, the odds ratios associated with cancer and with CVD equal 1.10 (95\%CI: 1.01, 1.19) and 1.13 (95\%CI: 1.04, 1.22) respectively. As expected, the baseline hazards for cancer and cardiovascular diseases are both exponentially increasing with age.

The covariance of $V_{c}$ and $V_{c v d}$ can be derived as (van den Berg, Lindeboom and Ridder, 1994):

$$
\operatorname{cov}\left(V_{c}, V_{c v d}\right)=\left(\begin{array}{llll}
p_{11} & p_{22}-p_{12} & p_{21}
\end{array}\right)\left(v_{c}^{1}-v_{c}^{2}\right)\left(v_{c v d}^{1}-v_{c v d}^{2}\right)
$$

The estimation results indicate that the probabilities $p_{21}$ and $p_{12}$ equal 0 and that $v_{c}^{1}<v_{c}^{2}$ and $v_{c v d}^{1}<v_{c v d}^{2}$. Apart from, $p_{21}$ and $p_{12}$, all other parameters of the mixing distribution are significantly different from zero. The results thus indicate that they are two groups of individuals: one relatively healthy, having lower risks of dying via cancer or cardiovascular diseases, and one relatively unhealthy, having higher risks of dying via cancer or cardiovascular diseases (see Table 8). The estimates of the parameters of the mixing 
distribution (indeed) imply a positive covariance that is significantly different from zero (cov $=0.69$, se $=4.77)$. This implies that it is important to control for correlated unobserved heterogeneity. Finally, comparing parameters associated with early life conditions for cancer and cardiovascular diseases in Tables 6 and 7 (independent CRM) and in Table 8 (dependent CRM) shows that all significant parameters in Table 8 are substantially larger in absolute value. This indicates that not taking into account the correlation between cancer and cardiovascular mortality into account leads to an underestimation of the effects of early life (economic) conditions on mortality later in life. Indeed, dynamic selection may bias the parameters towards zero (Lancaster, 1990).

Residual life expectancies Table 9 reports computed residual life expectancies for both the independent and the dependent CRM. Life expectancies are calculated using equation (6). For reasons of conciseness, we only report the residual life expectancies for cancer and cardiovascular diseases. A male exposed in utero (during his first year of life, respectively) to a severe economic recession lose on average about $7.3 \%$ (3.6\%, respectively) of his residual life expectancy at age 60 . This is because he is more likely to have cancer than a male who was unexposed to a recession in early life. These figures equal $5.5 \%$ and $6.9 \%$ for females. The residual life expectancies for cancer mortality are largely in agreement in the independent and the dependent CRM. The residual life expectancies for cardiovascular mortality differ greatly. However recall that the cardiovascular estimation results for males are not significant in both models and that they are for females only borderline significant in the independent model and strongly significant in the dependent CRM.

$<$ Here Table $9>$ 


\section{DISCUSSION AND CONCLUSIONS}

The aim of this paper is to provide evidence suggesting causal relationships between early life economic conditions and all-cause and cause-specific mortality during adulthood, in a general population and allowing for dependence between mortality risks. We use the cyclical component of the Gross Domestic Product (GDP) as an exogenous indicator of economic condition in early life to demonstrate the causal effects on all-cause and causespecific mortality. Our study shows that early life economic conditions affect all-cause mortality for both genders. With respect to cause-specific mortality, models are estimated assuming, first, independence among the various risks and assuming, second, dependent risks for cancer and cardiovascular mortality. The mortality due to cancer appears to be affected by early life economic conditions for both genders, while the mortality due to cardiovascular diseases is only affected by early life economic conditions for females. Being exposed to a severe economic recession in early life results in a loss of residual life expectancy at age 60 of about $4 \%$ for males and about $7 \%$ for females.

The results regarding all-cause mortality and mortality due to cardiovascular diseases are comparable with results of earlier studies, although studies do not always estimate models by gender (van den Berg et al. 2006, van den Berg et al. 2008, 2011). With respect to allcause mortality, the study of van den Berg et al. (2006), which is also based on the HSN data, shows significant effects only for males whereas our study finds significant effects for both genders. However, the differences between the two studies could be explained by the fact that the HSN individuals included in the study of van den Berg et al. (2006) are born in 18121902, before the demographic transition that roughly took place in the 1870's (and not in 1880-1918 as in our study). As mentioned earlier, the Netherlands underwent since 1870 big changes resulting in reduced death rates and higher life expectancy for newborns (Wintle 2000, van Poppel et al. 2005). 
Second, most relevant literature shows associations between socioeconomic status in early life and cardiovascular mortality (Galobardes et al. 2004, 2008, van den Berg et al., 2011). Our study demonstrates significant effects for females only. It is interesting to note that the parameters become strongly significant only when we allow for dependence of risks between cancer and cardiovascular mortality risks by means of unobserved individual components.

Third, the present study finds effects of exposure to adverse economic conditions in early life on mortality due to cancer. The medical evidence does not lead us to suspect that the overall cancer mortality rate late in life is much higher in case of adverse economic conditions around birth. In fact, Ahlgren et al. (2007) demonstrate positive associations between birth weight and the rates at which almost all types of cancer occur at higher ages. By analogy to the negative association between birth weight and CVD, this actually suggests that improved economic conditions at birth might lead to a higher rate of certain cancers. Other studies do not show any associations between socioeconomic conditions in early life or during childhood with overall cancer mortality, but show positive associations with specific cancer types (Galobardes et al. 2004, 2008). We have re-estimated our models distinguishing between several types of cancers. We find significant effects for colon cancer for males. Research has shown evidence that household income during childhood is negatively associated to smokingrelated cancers later in life (Frijters et al. 2010). We find similar results for females only, indicating that good economic conditions during first year of life lead to lower mortality rates later in life for smoking-related cancers ${ }^{7}$ for females. No effects are found for smoking and non-smoking related cancers for males (results not shown).

\footnotetext{
${ }^{7}$ Smoking-related cancers include leukaemia, as well as cancer of the lungs, upper respiratory tract, oesophagus, stomach, pancreas, kidney, liver, colon, cervix and prostate (Brownson et al. 1993, Plaskon et al. 2003, Sasco et al. 2004).
} 
Fourth, regarding other causes of death, we find statistically significant effects of being exposed to recessions in early life on mortality due to chronic respiratory diseases (for females) and external causes of death (for females), and for other causes of death (for both genders). The result regarding external causes of death is unexpected, but the parameter is very large compared to other parameters, which is probably due to the relatively small number of observed failures for this category. Moreover, the parameter is only statistically significant at a $10 \%$ level in model specification 2.

Fifth, in our study, the results for females are more pronounced compared to those for males. As outlined at the beginning of section 3, female adult health may be more influenced by childhood conditions than for males because of biological differences or the different types of roles males and females have in society.

All this above hints at a causal link between early life economic conditions and morbidity and mortality during adulthood. The results of the models assuming dependence between the causes of death suggest that the mortality risks for cancer and cardiovascular diseases are related to each other and that it is important to adjust for this correlation. However, it is important to realize that several factors may disturb the assessment of causal effects. For instance, the composition of cohorts born during the economic crisis may be different from that outside the crisis period. In earlier study by Van den Berg, Lindeboom and Lopez (2009), using HSN data (as we do) examine how the size and the composition by social class of a birth year cohort changes with the cyclical indicator of the business cycle at birth. They conclude that there are no such effects. Other studies with data from Northwest Europe from around 1900 also fail to find that the social-class composition of newborns is systematically related to fluctuations in macro indicators early-life conditions. Kareholt (2001) studies Swedish birth cohorts from 1897-1938 and examines whether the fraction of newborns whose father had a blue (vs. white collar) occupation varies with the state of the 
business cycle as measured by the annual change in the inflow into poor relief. The results show that there is no significant difference among male and among female newborns. Van den Berg, Doblhammer and Christensen (2011) find that there is no significant relation between the level of education and the business cycle in the birth year (1873-1906). The same applies to social class and region. In sum, the evidence suggests that the composition of newborns in terms of social class, education, and other personal characteristics does not vary systematically over the business cycle.

This study suggests that interventions aimed at the improvement of economic conditions of pregnant women and/or infants may contribute to the prevention of cancer, cardiovascular diseases and chronic respiratory diseases during adulthood. Consequently, the benefits of early life interventions in period of harshness may be even larger than assumed until now. Further research is required to test whether the observed relationships result from a direct effect of adverse economic conditions on the incidence of chronic diseases during adulthood, as suggested by the theory of the "fetal origins of diseases" of Barker (1992), or of indirect effects through life as suggested by the chain of risk model of Kuh and Ben-Shlomo (2004). 


\section{REFERENCES}

Abbring, J. H. and G. J. van den Berg. 2003. The identifiability of the mixed proportional hazards competing risks model. Journal of the Royal Statistical Society 65(3):701-710.

Ahlgren, M., J. Wohlfahrt, L.W. Olsen, T.I.A. Sørensen and M. Melbye. 2007. Birth weight and risk of cancer, Cancer 110:412-419.

Almond, D. V. 2006. Is the 1918 Influenza Pandemic over? Long-term effects of in utero Influenza exposure in the post 1940 U.S. population. Journal of Political Economy 114:672712.

Alzheimer's Association. 2009. 2009 Alzheimer's disease facts and figures. Alzheimer's and Dementia 5:234-270.

Barker, D. 1992. Foetal and infant origins of adult diseases. BMJ Publishing Group, London.

Bengtsson, T. and M. Lindstrom. 2003. Airborne infectious diseases during infancy and mortality in later life in southern Sweden, 1766-1894. International Journal of Epidemiology 32:286-294.

van den Berg, G. J., G. Doblhammer, and K. Christensen. 2011. Being born under adverse economic conditions leads to a higher cardiovascular mortality rate later in life: Evidence based on individuals born at different stages of the business cycle. Demography 48(2): 507530.

van den Berg, G. J., G. Doblhammer, and K. Christensen. 2009. Exogenous determinants of early-life conditions, and mortality later in life. Social Science \& Medicine 68:1591-1598.

Van den Berg GJ, M. Lindeboom, and M. Lopez. 2009. Inequality in individual mortality and economic conditions earlier in life. Social Science \& Medicine 69(9):1360-1367.

van den Berg, G. J., M. Lindeboom, and F. Portrait. 2006. Economic Conditions Early in Life and Individual Mortality. American Economic Review 96:290-302.

van den Berg, G. J., M. Lindeboom, and G. Ridder. 1994. Attrition in longitudinal panel data and the empirical analysis of dynamic labour market behaviour. Journal of Applied Econometrics 9(4):421-435.

Brownson, R. C., T. E. Novotny, and M. C. Perry. 1993. Cigarette Smoking and Adult Leukemia: A Meta-analysis. Archives of Internal Medicine 153:469-475. 
Cameron, A. C. and P. K. Trivedi. 2005. Microeconometrics: Methods and Applications. Cambridge University Press, New York.

CBS. 1935. Groote Internationale Lijst van Doodsoorzaken 1935. CBS, 's Gravenhage.

CBS. 1940. Groote Internationale Lijst van Doodsoorzaken 1938. CBS, 's Gravenhage.

Chapman, B.P. 2009. Can the influence of childhood SES on Men and Women's adult Body Mass be explained by adult SES or personality? Findings from a national sample. Health Psychology 28(4):419-427.

Chen, Y. and L. Zhou. 2007. The Long-term Health and Economic Consequences of the 19591961 Famine in China. Journal of Health Economics 26:659-681.

Corrada, M. M., R. Brookmeyer, D. Berlau, A. Paganini-Hill, and C. H. Kawas. 2008. Prevalence of dementia after age 90: results from the 90+ study. Neurology 71:337-343.

Factor-Litvak P, Susser E (2004) “A life course approach to neuropsychiatric outcomes” in Kuh D, Ben-Shlomo Y “A life course approach to chronic disease epidemiology”, 2nd edition, Oxford University Press, Oxford.

Frijters, P., T. J. Hatton, R. M. Martin, and M. A. Shields. 2010. Childhood economic conditions and length of life: Evidence from the UK Boyd Orr cohort, 1937-2005. Journal of Health Economics 29:39-47.

Galobardes, B., J. W. Lynch, and G. Davey Smith. 2008. Is the association between childhood socioeconomic circumstances and cause-specific mortality established? Update of a systematic review. Journal of Epidemiology \& Community Health 62:387-390.

Galobardes, B., J. W. Lynch, and G. Davey Smith. 2004. Childhood Socioeconomic Circumstances and Cause-specific Mortality in Adulthood: Systematic Review and Interpretation. Epidemiologic Reviews 26:7-21.

Hall, C. B., J. Verghese, M. Sliwinski, Z. Chen, M. Katz, C. Derby, and R. B. Lipton. 2005. Dementia incidence may increase more slowly after age 90: results from the Bronx Aging Study. Neurology 65:882-886.

Hamil-Luker, J. and A. M. O'Rand. 2007. Gender Differences in the Link between Childhood Socioeconomic Conditions and Heart Attack Risk in Adulthood. Demography 44:137-158.

Harteloh, P., K. de Bruin, and J. Kardaun. 2010. The reliability of cause-of-death coding in The Netherlands. European Journal of Epidemiology 25:531-538. 
Hodrick, R. J. and E. C. Prescott. 1997. Postwar U.S. Business Cycles: An Empirical Investigation. Journal of Money, Credit and Banking 29:1-16.

Honoré, B. E. and A. Lleras-Muney. 2006. Bounds in Competing Risks Models and the War on Cancer. Econometrica 74:1675-1698.

Janssen, F. and A. E. Kunst. 2004. ICD coding changes and discontinuities in trends in causespecific mortality in six European countries, 1950-99. Bulletin of the World Health Organization 82:904-913.

Kareholt, I. 2001. The long shadow of socioeconomic conditions in childhood: do they affect class inequalities in mortality? In: J.O. Jonsson and C. Mills, (eds.), Cradle to Grave: Lifecourse Change in Modern Sweden, Sociology Press, Durham.

Kleinbaum, D. G. and Klein M. 2005. Survival Analysis: A Self-learning Text, Second ed. Springer, New York.

Koupil, I., D. Shestov, P. Sparén, S. Plavinskaja, N. Parfenova, and D. Vagerö. 2007. Blood pressure, hypertension and mortality from circulatory disease in men and women who survived the siege of Leningrad. European Journal of Epidemiology 22:223-234.

Kuh, D. and Y. Ben-Shlomo. 2004. A Life Course Approach to Chronic Disease Epidemiology, Second ed. Oxford university press, Oxford.

Lancaster, T. 1990. The Econometric Analysis of Transition Data. Cambridge University Press, Cambridge.

Landrigan, P. J., B. Sonawane, R. N. Butler, L. Trasande, R. Callan and D. Droller. 2005. Early environmental origins of neurodegenerative disease in later life. Environmental Health Perspectives 113(9):1230-33.

van Leeuwen, M. H. and I. Maas. A short note on HISCLASS. 2005. Unpublished Work.

van Leeuwen, M. H., I. Maas, and A. Miles. 2002. HISCO: Historical International Standard Classification of Occupations. Leuven University Press, Leuven.

Lindeboom, M., F. Portrait and G.J. 2010. Long-run longevity effects of a nutritional shock early in life: the Dutch potato famine of 1846-1847. Journal of Health Economics 29(5):61729. 
Lowan, A. N. 1972. Orthogonal Polynomials, pp. 771-802 In M. Abramowitz and I. A. Stegun (eds.), Handbook of Mathematical Functions with Formulas, Graphs, and Mathematical Tables. Dover, New York.

Luo, Y. and Waite, L.J. 2005. The impact of childhood and adult SES on physical, mental and cognitive well-being in later life. Journal of Gerontology B 60(2):S93-S101.

Maddison, A. Statistics on World Population, GDP and Per Capita GDP, 1-2006 AD. 2009.

Mandemakers, K. 2000. Netherlands - Historical Sample of the Netherlands, pp. 149-178 In P. K. Hall, R. McCaa, and G. Thorvaldsen (eds.), Handbook of International Historical Microdata for Population Research. Minnesota Population Center, Minneapolis.

Miller, D. B. and J. P. O’Callaghan. 2008. Do early-life insults contribute to the late-life development of Parkinson and Alzheimer diseases? Metabolism 57(2):S44-49.

Moeyes, P. 2001. Buiten schot: Nederland tijdens de Eerste Wereldoorlog: 1914-1918. De Arbeiderspers, Antwerpen.

Newnham, J. and M. Ross. Early Life Origins of Human Health and Disease. 2009. Basel, Karger.

Plaskon, L. A., D. F. Penson, T. L. Vaughan, and J. L. Stanford. 2003. Cigarette smoking and risk of prostate cancer in middle-aged men. Cancer epidemiology, biomarkers \& prevention: a publication of the American Association for Cancer Research, cosponsored by the American Society of Preventive Oncology 12:604-609.

van Poppel, F., I. Deerenberg, J. Wolleswinkel-Van den Bosch, and P. Ekamper. 2005. Hoe lang leefden wij? Historische veranderingen in de levensduur en het doodsoorzakenpatroon. Bevolkingstrends 53:18-25.

Sasco, A. J., M. B. Secretan, and K. Straif. 2004. Tobacco smoking and cancer: a brief review of recent epidemiological evidence. Lung Cancer 45:S3-S9.

StataCorp. Stata Statistical Software: Release 10. 2007. College Station, TX, StataCorp LP.

van der Velden, L. F. J., A. L. Francke, L. Hingstman, and D. L. Willems. 2009. Dying from cancer or other chronic diseases in the Netherlands: ten-year trends derived from death certificate data. BMC Palliative Care 8:4.

Vugs, R. 2002. Many houses mourned: the Spanish flu in the Netherlands (In Dutch: In veel huizen wordt gerouwd: de Spaanse griep in Nederland.) Aspekt, Soesterberg. 
W.H.O. 2005. Chronic diseases and their common risk factors. Facing the facts \#1.

Wienke, A., K. Christensen, A. Skytthe, and A. I. Yashin. 2002. Genetic analysis of cause of death in a mixture model of bivariate lifetime data. Statistical Modelling 2:89-102.

Wintle, M. 2000. An economic and social history of the Netherlands, 1880-1920: demographic, economic and social transition, 1 ed. Cambridge University Press, Cambridge.

van Zanden, J. L. 1998. The best of both worlds: Catching up 1914-1929, pp. 91-105 The economic history of the Netherlands, 1914-1995: a small open economy in the 'long' twentieh century. Routledge, London. 
Figure 1 Availability of information on causes of death in the HSN cohorts (1863-1918)

\section{by birth year.}

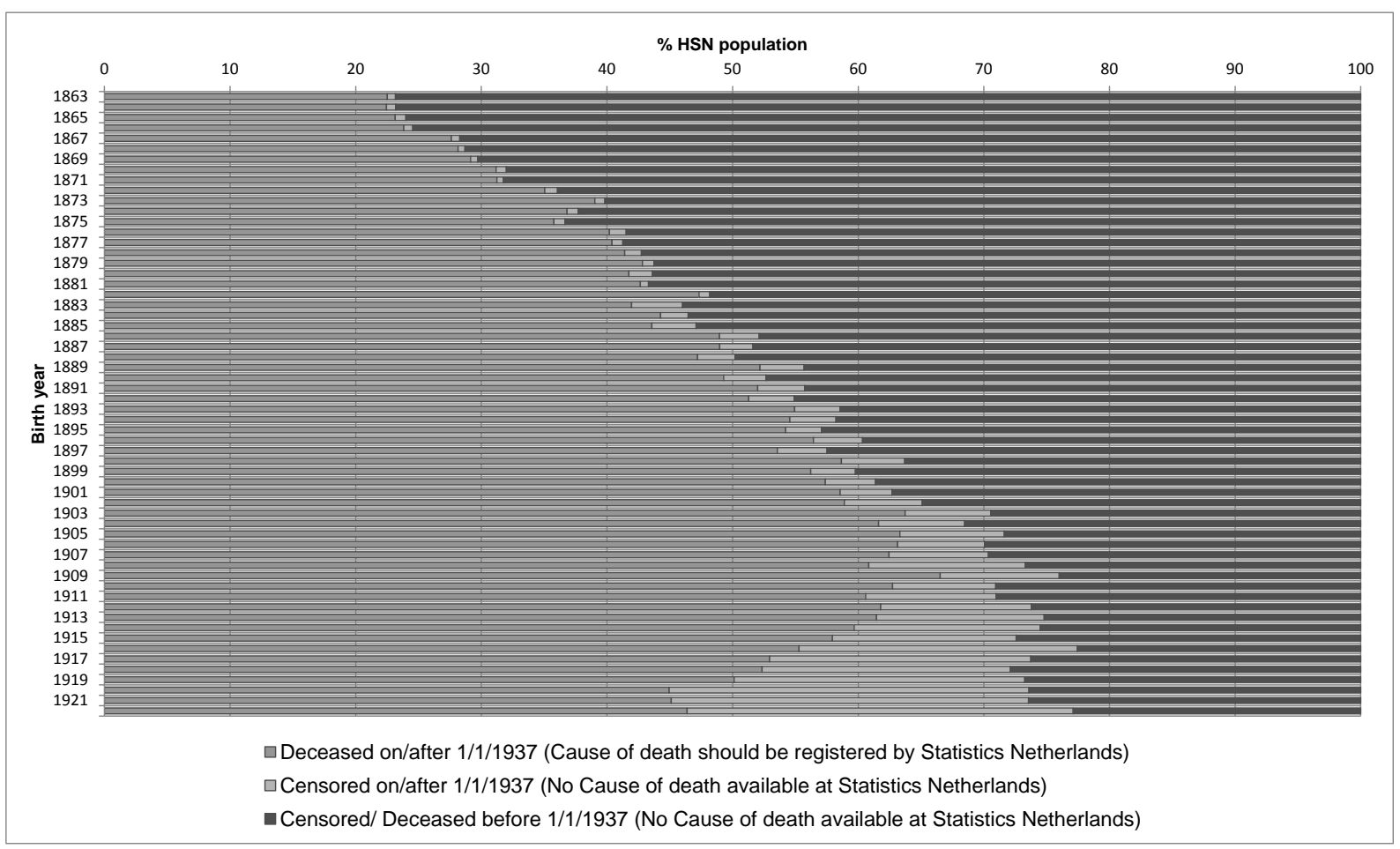


Figure 2 Annual Log Real Gross Domestic Product Per Capita: Log(GDPpc).

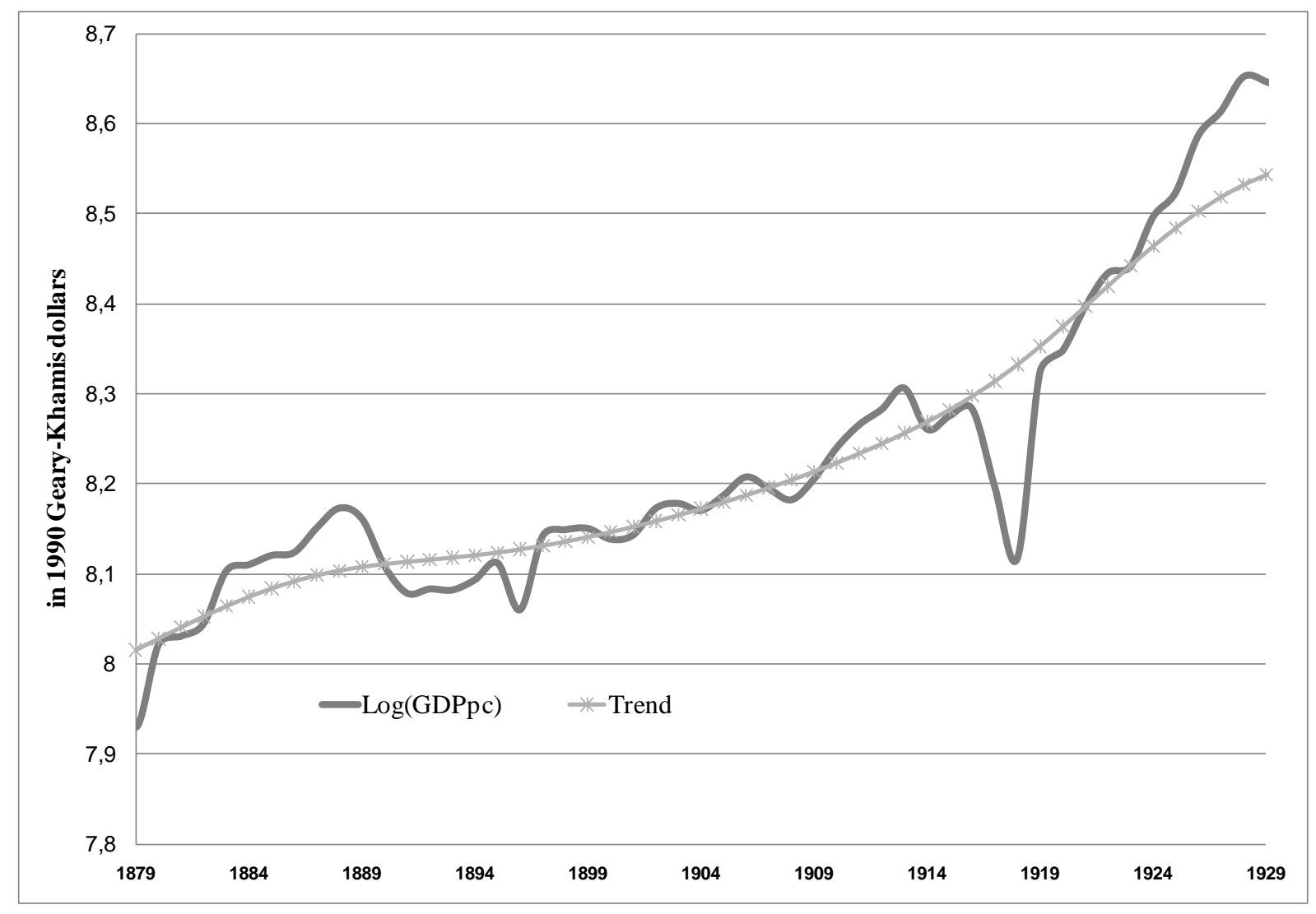

Gross Domestic Product measured in 1990 Gaery-Khamis dollars, data provided by Maddison (2009). Trend calculated using Hodrick-Prescott Methods. 
Figure 3 The economic cycle and the transitory component in the mean lifetime in the birth cohort 1880-1918, conditional on survival until age 57.

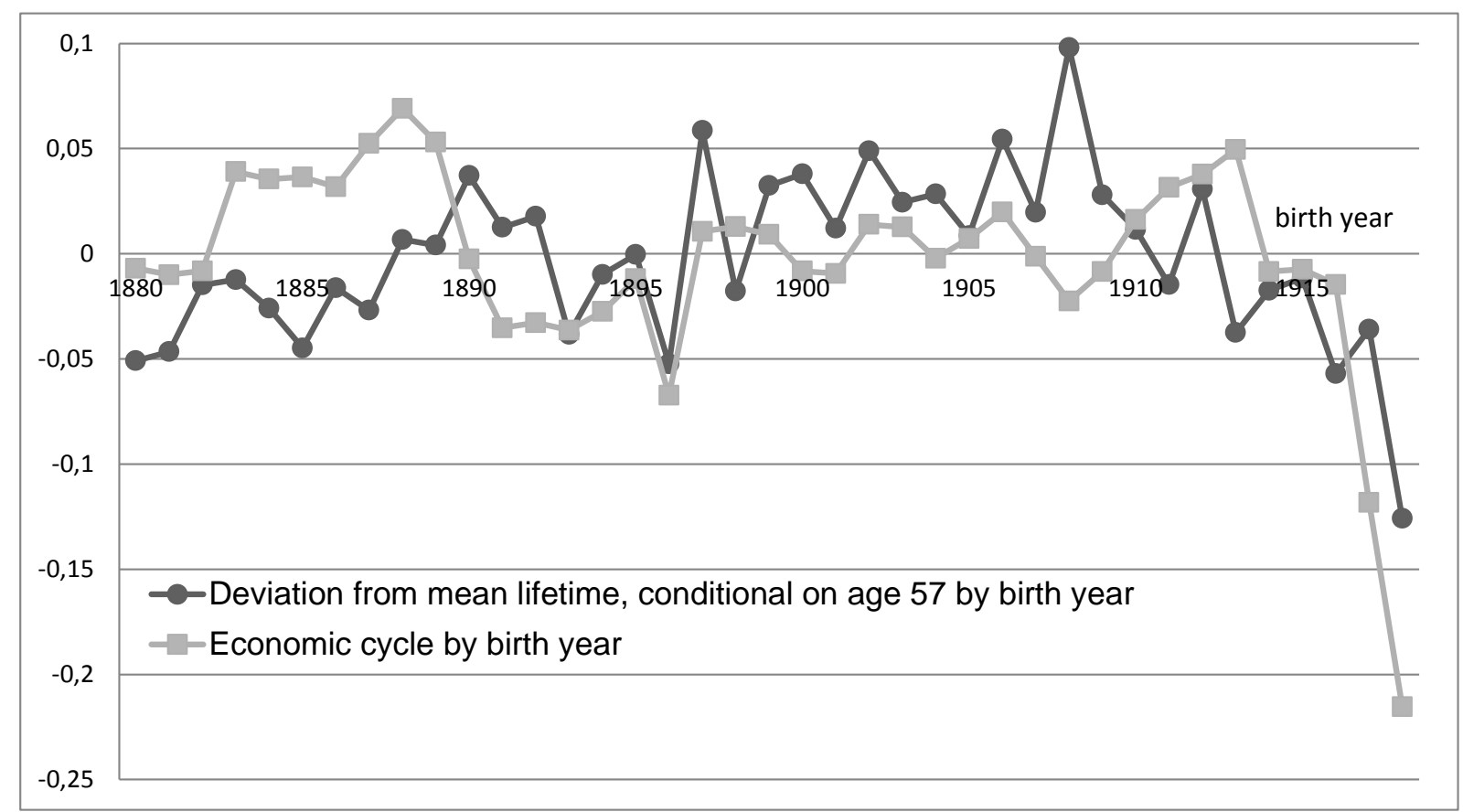


Figure 4 Kaplan-Meier Survival Curves for Males who survived at least until 1937 and born in the period 1910-1913 (economic expansion) or 1914-1918 (economic recession).

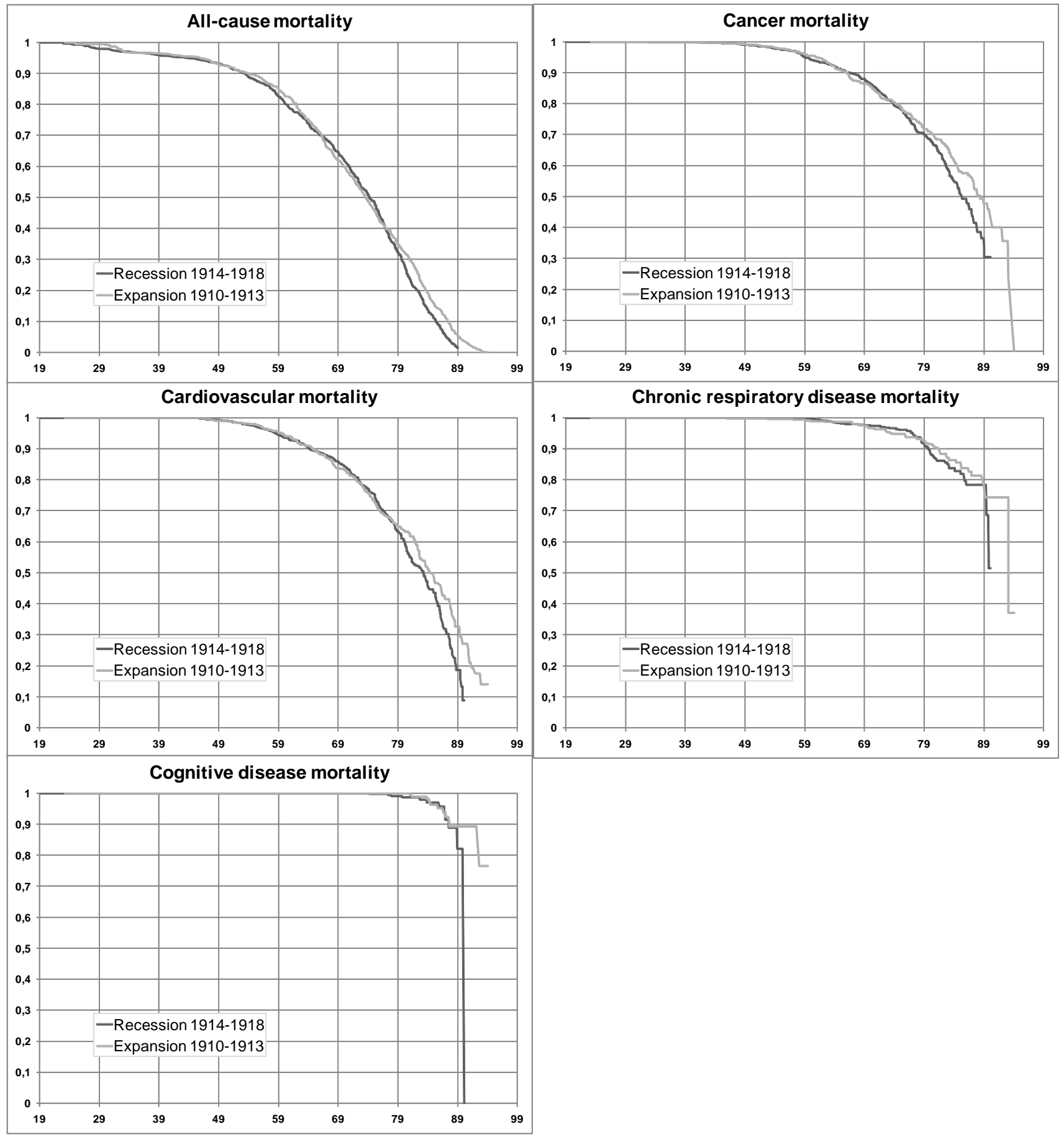


Figure 5 Kaplan-Meier Survival Curves for Females who survived at least until 1937 and born in the period 1910-1913 (economic expansion) or 1914-1918 (economic recession).
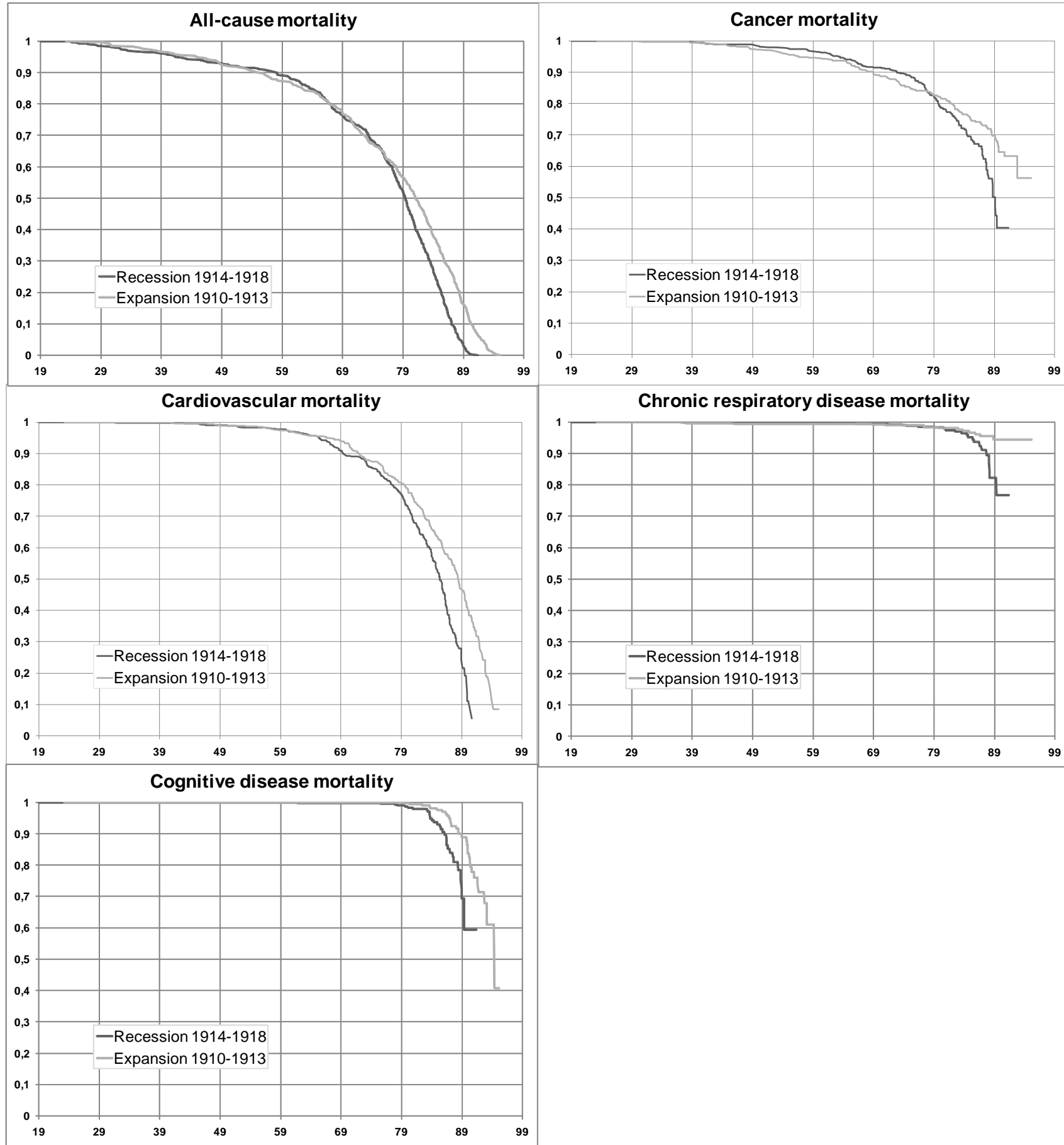
Figure 6 Contemporaneous effect of other time-varying macro conditions (Chebyshev's polynomials, Independent Competing Risks Models).

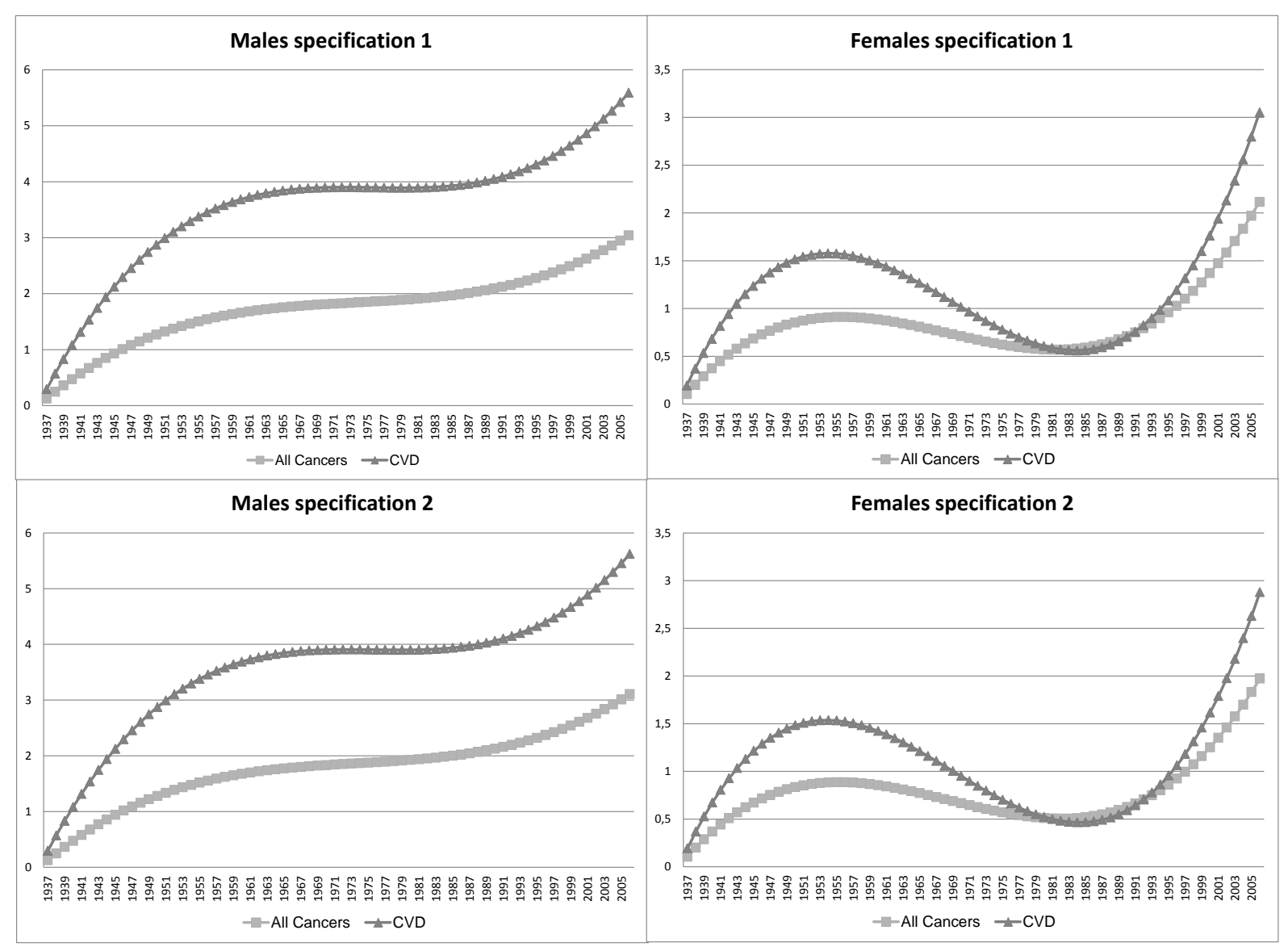

Specification 1 only corrects for GDP variations during pregnancy. Specification 2 corrects for GDP variations during the first year of life. 
Table 1 Concordance table linking ICD codes used in empirical analyses.

\begin{tabular}{|c|c|c|c|c|c|c|}
\hline Cause of death & ICD-4 & ICD-5 & ICD-6 \& ICD-7 & ICD-8 & ICD-9 & ICD-10 \\
\hline Infectious and parasitic diseases & 001-099 & 009-099 & 001-138 & $001-136$ & 001-139 & A01-B99 \\
\hline Pneumonia/Influenza & $12-13,457-466$ & $51-52,455-462$ & $480-483,490-493$ & $\begin{array}{c}470-474,480-483 \\
485-486\end{array}$ & $480-487$ & $\mathrm{~J} 10-\mathrm{J} 18$ \\
\hline Cancer of the oesophagus & $120-121$ & $115-116$ & 150 & 150 & 150 & $\mathrm{C} 15$ \\
\hline Cancer of the stomach & $122-124$ & $117-119$ & 151 & 151 & 1515 & C16 \\
\hline Cancer of the colorectum & $130,131,140-145$ & $127,130,131$ & $153-154$ & $153-154$ & $153-154$ & $\mathrm{C} 18-\mathrm{C} 21$ \\
\hline Cancer of the pancreas & 136,137 & 136,137 & 157 & 157 & 157 & $\mathrm{C} 25$ \\
\hline Cancer of the upper repiratory tract & $100-117,147-150$ & $104-114,142-143$ & $140-148,160,161$ & $140-149,160,161$ & $140-149,160,161$ & $\mathrm{COO}-\mathrm{C} 14, \mathrm{C} 30-\mathrm{C} 32$ \\
\hline Cancer of the lung & $151-155$ & $144-145$ & $162-163$ & 162 & 162 & C33-C34 \\
\hline Cancer of the breast & 164 & 159 & 170 & 174 & $174-175$ & $\mathrm{C} 50$ \\
\hline Cancer of the prostate & 173,179 & $167-168$ & 177 & 185 & 185 & C61 \\
\hline Cancer of the bladder & 202,211 & 176,179 & 181 & 188 & 188 & $\mathrm{C} 67$ \\
\hline Cancer of the kidney & 201,210 & 175,178 & 180 & 189 & 189 & C64-C66, C68 \\
\hline Cancer, unspecified & 200 & 201 & $198-199,230-239$ & $195-199,230-239$ & $195-199,235-239$ & C76-C80, C97, D37-D48 \\
\hline \multirow[t]{2}{*}{ Other Cancers } & Rest & Rest & Rest & Rest & Rest & Rest \\
\hline & $(100-249)$ & $(100-234)$ & $(140-239,294)$ & $(140-239)$ & $(140-239)$ & (C00-D48) \\
\hline Diabetes mellitus & 253 & $255-256$ & 260 & 250 & 250 & E10-E14 \\
\hline Dementia and Alzheimer disease & 780 & $790-792$ & $304-306$ & 290,293 & 290,331 & $\mathrm{~F} 00, \mathrm{~F} 01, \mathrm{~F} 03, \mathrm{G} 30$ \\
\hline Ischeamic heart disease & 375 & 420 & 420 & $410-414$ & $410-414$ & $120-125$ \\
\hline Other heart diseases & $350-394$ & $400-431$ & $\begin{array}{l}400-402,410-416,421- \\
422,430-434,440-448\end{array}$ & $\begin{array}{c}390-398,400-404 \\
420-425,427-429\end{array}$ & $\begin{array}{c}390-398,401-405 \\
416,420-429\end{array}$ & $100-113,115,127,130-152$ \\
\hline Cerebrovascular diseases & 309 & $359-360$ & $430-434,436-438$ & $430-434,436-438$ & $430-434,436-438$ & $160-169$ \\
\hline \multirow[t]{2}{*}{ Other circulatory diseases } & Rest & Rest & Rest & Rest & Rest & Rest \\
\hline & $(350-449)$ & $(400-444)$ & $(400-468)$ & $\begin{array}{c}\text { (390-458, excluding } \\
435 \& 446)\end{array}$ & $\begin{array}{c}\text { (390-459, excluding } \\
435 \& 436)\end{array}$ & (10O-199) \\
\hline COPD/ Astma & $451-453,484,482$ & $451-453,471,472$ & $501,502,526,527,241$ & $490-493,518$ & $490-494,496$ & $\mathrm{~J} 40-\mathrm{J} 47$ \\
\hline Senillity & 790 & 795 & 794 & 794 & 797 & R54 \\
\hline \multirow[t]{2}{*}{ Other symptoms and ill-defined } & Rest & Rest & Rest & Rest & Rest & Rest \\
\hline & 871-872 & $950-953$ & $(780-795)$ & $(780-796)$ & $(780-799)$ & (R00-R99) \\
\hline \multirow[t]{2}{*}{ Other diseases } & Rest & Rest & Rest & Rest & Rest & Rest \\
\hline & & & $(001-795)$ & $(001-796)$ & $(001-799)$ & (A00-R99) \\
\hline Accidental fall & $846-852$ & $903-908$ & E900-904 & E880-887 & E880-888 & W00-W19, X59 \\
\hline Suicide & $800-818$ & $800-817$ & E970-E979 & E950-E959 & E950-E959 & $X 60-X 84$ \\
\hline \multirow[t]{2}{*}{ Other external causes } & Rest & Rest & Rest & Rest & Rest & Rest \\
\hline & $(800-870)$ & $(800-928)$ & (E800-999) & (E800-999) & (E800-999) & (V01-Y98) \\
\hline
\end{tabular}


Table 2 Causes of death by birth cohort and gender, conditional on Survival until January $1^{\text {st }}, 1937$.

\begin{tabular}{|l|c|c|c|c|c|c|c|c|c|c|c|}
\hline & \multicolumn{7}{|c|}{ birth cohort } & \multicolumn{3}{c|}{ Total } \\
& \multicolumn{7}{|c|}{$1880-1889$} & $1890-1899$ & $1900-1909$ & $1910-1918$ & \multicolumn{2}{|c|}{} \\
\hline & Male & Female & Male & Female & Male & Female & Male & Female & $\#$ & $\%$ \\
\hline All Cancers & 19,3 & 17,0 & 22,0 & 19,7 & 26,5 & 18,4 & 23,7 & 17,7 & 3164 & 20,7 \\
\hline CVD & 42,5 & 47,6 & 41,6 & 43,6 & 37,2 & 40,7 & 32,0 & 31,1 & 6115 & 39,9 \\
\hline Chronic respiratory diseases & 2,9 & 2,1 & 5,5 & 1,5 & 5,5 & 1,6 & 6,4 & 2,4 & 534 & 3,5 \\
\hline Cognitive diseases & 0,9 & 1,0 & 0,3 & 1,1 & 0,8 & 3,0 & 1,2 & 3,4 & 213 & 1,4 \\
\hline External & 4,1 & 3,7 & 3,9 & 3,4 & 3,5 & 3,0 & 3,5 & 2,4 & 525 & 3,4 \\
\hline Others & 21,4 & 20,8 & 18,2 & 23,0 & 14,4 & 21,9 & 14,5 & 18,7 & 2943 & 19,2 \\
\hline Not Available & 8,9 & 7,8 & 8,5 & 7,7 & 12,1 & 11,4 & 18,7 & 24,3 & 1822 & 11,9 \\
\hline Total \# & 1740 & 1823 & 2241 & 2287 & 2050 & 1989 & 1652 & 1534 & 15316 & \\
\hline
\end{tabular}

All Cancers of table 1 are grouped into one category, Cardiovascular diseases (CVD) include ischaemic heart diseases, cerebrovascular diseases and other heart or circulatory diseases. Chronic respiratory diseases includes chronic obstructive pulmonary diseases and asthma. Cognitive diseases are different types of dementia. Other External causes are e.g. poisoning, (trafic) accidents, homocide, suicide. Others are all not listed causes that are mentioned in table 1. Not available are the HSN individuals with no known cause of death at CBS. 
Table 3 Sample characteristics

\begin{tabular}{|c|c|c|}
\hline & $\%$ Males & $\%$ Females \\
\hline Born in 1980-1918 & $\mathrm{n}=7,300$ & $n=7,220$ \\
\hline Mother married at the time of birth & 99.4 & 99.4 \\
\hline Mother marital status unknown at the time of birth & 0.4 & 0.3 \\
\hline Father informer of birth & 96.7 & 97.4 \\
\hline Father literate & 93.1 & 93.6 \\
\hline (1) higher managers & 0.9 & 0.9 \\
\hline (2) higher professionals & 5.4 & 5.9 \\
\hline (3) lower managers & 3.5 & 3.5 \\
\hline (4) lower professionals & 8.9 & 8.8 \\
\hline (5) lower clerical and sales & 2.0 & 2.3 \\
\hline (6) foremen & 0.1 & 0.1 \\
\hline (7) medium-skilled workers & 19.4 & 19.8 \\
\hline (8) farmers & 14.6 & 14.4 \\
\hline (9) lower-skilled workers & 13.0 & 13.1 \\
\hline (10) lower-skilled farm workers & 2.1 & 1.9 \\
\hline (11) unskilled workers & 8.6 & 8.9 \\
\hline (12) unskilled farm workers & 21.4 & 20.3 \\
\hline Born in urban area & 27.6 & 28.0 \\
\hline Born in province & 8.6 & 8.7 \\
\hline Groningen & 5.8 & 5.3 \\
\hline Drenthe & 3.1 & 2.8 \\
\hline Overijssel & 6.7 & 6.6 \\
\hline Gelderland & 11.0 & 9.8 \\
\hline Utrecht & 6.7 & 7.1 \\
\hline Noord-Holland & 16.5 & 17.6 \\
\hline Zuid-Holland & 20.4 & 20.7 \\
\hline Zeeland & 5.4 & 5.5 \\
\hline Noord-Brabant & 10.3 & 10.6 \\
\hline Limburg & 5.5 & 5.3 \\
\hline
\end{tabular}


Table 4. Estimation results All-cause mortality Extended Cox Model for different characterisations of economic situation in early life, fully adjusted (excerpt).

\begin{tabular}{|c|c|c|c|c|c|c|c|c|c|c|c|c|}
\hline \multirow{2}{*}{$\begin{array}{r}\text { Parameter Estimates All-cause mortality } \\
\text { (failed/total observed) }\end{array}$} & \multicolumn{3}{|c|}{ specification 1} & \multicolumn{3}{|c|}{ specification 2} & \multicolumn{3}{|c|}{ specification 3} & \multicolumn{3}{|c|}{ specification 4} \\
\hline & $\beta$ & $|\mathrm{t}|$ & & $\beta$ & $|\mathrm{t}|$ & & $\beta$ & $|\mathrm{t}|$ & & $\beta$ & $|\mathrm{t}|$ & \\
\hline \multicolumn{13}{|l|}{ Males (6615/7300) } \\
\hline during pregnancy & $-0,68$ & 2,1 & * & & & & $-0,49$ & 1,0 & & & & \\
\hline first life year & & & & $-0,61$ & 1,9 & † & $-0,25$ & 0,5 & & & & \\
\hline during pregnancy \& first life year & & & & & & & & & & $-0,73$ & 2,2 & * \\
\hline \multicolumn{13}{|l|}{ Females $(6470 / 7220)$} \\
\hline during pregnancy & $-1,20$ & 3,5 & 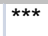 & & & & 0,15 & 0,3 & & & & \\
\hline first life year & & & & $-1,67$ & 4,9 & 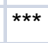 & $-1,78$ & 3,4 & $\star \star \star$ & & & \\
\hline during pregnancy \& first life year & & & & & & & & & & $-1,64$ & 4,5 & $\star \star \star$ \\
\hline
\end{tabular}

Specification 1 only corrects for GDP variations during pregnancy. Specification 2 corrects for GDP variations during the first year of life. Specification 3 includes both previous variables. Specification 4 includes the average cyclical GDP component during pregnancy and first year of life.

Fully Adjusted for other macro, socioeconomic and demographic conditions (results not shown). $\dagger<0.1 *<0.05 * *<0.01 * * *<0.001$

Table 5 Overall residual life expectancies at age 60 (\% difference compared to no recession).

\begin{tabular}{|l|c|c|c|c|}
\hline \multicolumn{5}{|l|}{ Residual Life Expectancies All-cause mortality at Age 60 } \\
\hline & No recession & Average $^{1}$ & Maximum \\
\hline & 0 & $-0,029$ & $-0,031$ & $-0,187$ \\
\hline Males & & & & \\
\hline during Pregnancy & 17,0 & $16.8(-0.8)$ & $16.1(-5.0)$ \\
\hline $\begin{array}{l}\text { during First life year } \\
\text { Females }\end{array}$ & 17,0 & $16.9(-0.8)$ & $16.2(-4.5)$ \\
\hline during Pregnancy & 20,1 & $19.9(-0.9)$ & $18.9(-6.0)$ \\
\hline during First life year & 20,3 & $20.0(-1.3)$ & $18.6(-8.3)$ \\
\hline
\end{tabular}

Average residual life expectancies at age 60 for our most observed individuals born in 1918 and exposed to different economic situations during different periods in early life. ${ }^{1}$ Average recession in our sample during pregnancy was -0.029 and during first life year -0.031 
Table 6 Estimation results Independent Competing Risk Models (Extended Cox Model) for different characterisations of economic conditions in early life, fully adjusted for males. (excerpt)

\begin{tabular}{|c|c|c|c|c|c|c|c|c|c|c|c|}
\hline Fully Adjusted Males & sper & icatio & & spec & icatio & sper & icatio & & spec & catio & \\
\hline cause of death (failed/total observed) & $\beta$ & $|\mathrm{t}|$ & & $\beta$ & $|\mathrm{t}|$ & $\beta$ & $|\mathrm{t}|$ & & $\beta$ & $|\mathrm{t}|$ & \\
\hline All Cancers $(1673 / 7300)$ & & & & & & & & & & & \\
\hline during pregnancy & $-1,24$ & 2,1 & * & & & $-1,77$ & 2,0 & * & & & \\
\hline first life year & & & & $-0,62$ & 1,0 & 0,71 & 0,8 & & & & \\
\hline during pregnancy \& first life year & & & & & & & & & $-1,06$ & 1,7 & $\dagger$ \\
\hline CVD $(2845 / 7300)$ & & & & & & & & & & & \\
\hline during pregnancy & $-0,29$ & 0,6 & & & & 0,19 & 0,2 & & & & \\
\hline first life year & & & & $-0,48$ & 1,0 & $-0,62$ & 0,8 & & & & \\
\hline during pregnancy \& first life year & & & & & & & & & $-0,44$ & 0,8 & \\
\hline Chronic respiratory diseases $(368 / 7300)$ & & & & & & & & & & & \\
\hline GDP Cycle: $\quad$ during pregnancy & $-1,27$ & 1,1 & & & & $-1,05$ & 0,6 & & & & \\
\hline first life year & & & & $-1,06$ & 0,9 & $-0,29$ & 0,2 & & & & \\
\hline during pregnancy \& first life year & & & & & & & & & $-1,33$ & 1,0 & \\
\hline Cognitive Diseases $(59 / 7300) \ddagger \diamond$ & & & & & & & & & & & \\
\hline GDP Cycle: $\quad$ during pregnancy & 1,63 & 0,5 & & & & 4,47 & 0,8 & & & & \\
\hline first life year & & & & $-0,33$ & 0,1 & $-3,54$ & $-0,7$ & & & & \\
\hline during pregnancy \& first life year & & & & & & & & & 0,72 & 0,2 & \\
\hline External $(277 / 7300) \diamond$ & & & & & & & & & & & \\
\hline during pregnancy & 0,00 & 0,0 & & & & 0,23 & 0,1 & & & & \\
\hline first life year & & & & $-0,13$ & 0,0 & $-0,30$ & 0,1 & & & & \\
\hline during pregnancy \& first life year & & & & & & & & & $-0,08$ & 0,0 & \\
\hline infancy & & & & & & & & & & & \\
\hline Other causes $(1204 / 7300)$ & & & & & & & & & & & \\
\hline GDP Cycle: $\quad$ during pregnancy & $-0,81$ & 1,1 & & & & 0,10 & 0,1 & & & & \\
\hline first life year & & & & $-1,11$ & 1,5 & $-1,19$ & 1,0 & & & & \\
\hline during pregnancy \& first life year & & & & & & & & & $-1,10$ & 1,4 & \\
\hline infancy & & & & & & & & & & & \\
\hline
\end{tabular}

Specification 1 only corrects for GDP variations during pregnancy. Specification 2 corrects for GDP variations during the first year of life. Specification 3 includes both previous variables.

Specification 4 includes the average cyclical GDP component during pregnancy and first year of life.

Fully Adjusted for other macro, socioeconomic and demographic conditions (results not shown). All cause-specific mortalities are mutually exclusive. $¥$ Not adjusted for World War II. $\diamond$ Not adjusted for marital status. $\dagger<0.1 *<0.05 * *<0.01 * * *<0.001$ 
Table 7 Estimation results Independent Competing Risk Models (Extended Cox Model) for different characterisations of economic conditions in early life, fully adjusted for females. (excerpt)

\begin{tabular}{|c|c|c|c|c|c|c|c|c|c|c|c|c|}
\hline \multirow{2}{*}{\begin{tabular}{|l|} 
Fully Adjusted for Females \\
cause of death (failed/total observed)
\end{tabular}} & \multicolumn{3}{|c|}{ specification 1} & \multicolumn{3}{|c|}{ specification 2} & \multicolumn{3}{|c|}{ specification 3} & \multicolumn{3}{|c|}{ specification 4} \\
\hline & $\beta$ & $|\mathrm{t}|$ & & $\beta$ & $|\mathrm{t}|$ & & $\beta$ & $|\mathrm{t}|$ & & $\beta$ & $|\mathrm{t}|$ & \\
\hline \\
\hline GDP Cycle: $\quad$ during pregnancy & $-1,32$ & 1,9 & $\dagger$ & & & & $-0,03$ & 0,0 & & & & \\
\hline first life year & & & & $-1,71$ & 2,4 & * & $-1,69$ & 1,6 & & & & \\
\hline during pregnancy \& first life year & & & & & & & & & & $-1,73$ & 2,3 & * \\
\hline \multicolumn{13}{|l|}{ CVD $(2982 / 7220)$} \\
\hline during pregnancy & $-0,95$ & 1,8 & $\dagger$ & & & & $-0,58$ & 0,7 & & & & \\
\hline first life year & & & & $-0,94$ & 1,8 & $\dagger$ & $-0,49$ & 0,6 & & & & \\
\hline during pregnancy \& first life year & & & & & & & & & & $-1,08$ & 1,9 & $\dagger$ \\
\hline \multicolumn{13}{|c|}{ Chronic respiratory diseases $(139 / 7220) 0$} \\
\hline GDP Cycle: $\quad$ during pregnancy & $-2,57$ & 1,2 & & & & & 2,32 & 0,7 & & & & \\
\hline first life year & & & & $-4,53$ & 2,2 & ** & $-6,19$ & 1,9 & * & & & \\
\hline during pregnancy \& first life year & & & & & & & & & & $-4,12$ & 1,8 & $\dagger$ \\
\hline \multicolumn{13}{|l|}{ Cognitive Diseases $(146 / 7220) \neq \diamond$} \\
\hline GDP Cycle: $\quad$ during pregnancy & $-1,03$ & 0,5 & & & & & $-0,51$ & 0,2 & & & & \\
\hline first life year & & & & $-1,06$ & 0,5 & & $-0,70$ & 0,2 & & & & \\
\hline during pregnancy \& first life year & & & & & & & & & & $-1,21$ & 0,5 & \\
\hline \multicolumn{13}{|l|}{ External $(222 / 7220) \diamond$} \\
\hline during pregnancy & $-1,06$ & 0,6 & & & & & 2,75 & 0,9 & & & & \\
\hline first life year & & & & $-2,89$ & 1,5 & & $-4,92$ & 1,7 & $\dagger$ & & & \\
\hline during pregnancy \& first life year & & & & & & & & & & $-2,27$ & 1,1 & \\
\hline infancy & & & & & & & & & & & & \\
\hline \multicolumn{13}{|l|}{ Other causes $(1550 / 7220)$} \\
\hline during pregnancy & $-1,59$ & 2,3 & * & & & & 0,95 & 0,9 & & & & \\
\hline first life year & & & & $-2,61$ & 3,8 & $\star \star \star$ & $-3,31$ & 3,1 & ** & & & \\
\hline during pregnancy \& first life year & & & & & & & & & & $-2,41$ & 3,2 & $\star \star$ \\
\hline
\end{tabular}

Specification 1 only corrects for GDP variations during pregnancy. Specification 2 corrects for GDP variations during the first year of life. Specification 3 includes both previous variables. Specification 4 includes the average cyclical GDP component during pregnancy and first year of life.

Fully Adjusted for other macro, socioeconomic and demographic conditions (results not shown). All cause-specific mortalities are mutually exclusive. $\ddagger$ Not adjusted for World War II. $\diamond$ Not adjusted for marital status. $\dagger<0.1 *<0.05 * *<0.01 * * *<0.001$ 
Table 8 Estimation results of the Dependent Competing Risk Model (5): Mixed Proportional Hazard Model for two different characterisations of economic conditions in early life, fully adjusted, by gender. (excerpt)

\begin{tabular}{|c|c|c|c|c|c|c|}
\hline \multirow{2}{*}{\begin{tabular}{|l} 
Males \\
cause of death (failed/total observed)
\end{tabular}} & \multicolumn{3}{|c|}{ specification 1} & \multicolumn{3}{|c|}{ specification 2} \\
\hline & $\beta$ & $|t|$ & & $\beta$ & $|t|$ & \\
\hline$p_{11}$ & 0,29 & 8,2 & 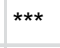 & 0,28 & 5,3 & *** \\
\hline$p_{12}$ & 0 & - & & 0 & - & \\
\hline$p_{21}$ & 0 & - & & 0 & - & \\
\hline$p_{22}$ & 0,71 & 20,5 & *** & 0,72 & 13,7 & *** \\
\hline \multicolumn{7}{|l|}{ All Cancers (1673/7300) } \\
\hline during pregnancy & $-1,45$ & 2,2 & * & & & \\
\hline first life year & & & & $-0,49$ & 0,7 & \\
\hline$v^{1, c} \quad$ (equal to constant $\boldsymbol{t}^{2, c}$ ) & $-1,45$ & 8,3 & *** & $-1,44$ & 7,4 & 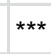 \\
\hline$v^{2, c} \quad$ (equal to constant) & $-30,73$ & 6,7 & *** & $-30,77$ & 6.7 & *** \\
\hline Baseline hazard parameter $\alpha$ & 0,09 & 20,3 & *** & 0,08 & 17,6 & *** \\
\hline \multicolumn{7}{|l|}{ CVD (2845/7300) } \\
\hline during pregnancy & $-0,85$ & 1,2 & & & & \\
\hline first life year & & & & $-0,48$ & 0,7 & \\
\hline$v^{1, c v d}$ (equal to constant $\left.t^{2, c v d}\right)$ & $-2,72$ & 16,2 & *** & $-2,68$ & 12,0 & 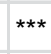 \\
\hline$v^{2, c v d}$ (equal to constant) & $-36,32$ & 7,3 & $\star \star \star$ & $-35,56$ & 6.5 & *夫* \\
\hline Baseline hazard parameter $\alpha$ & 0,15 & 24,9 & 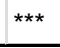 & 0,15 & 18,0 & $\star \star \star ~$ \\
\hline Females & \multicolumn{3}{|c|}{ specification 1} & \multicolumn{3}{|c|}{ specification 2} \\
\hline cause of death (failed/total observed) & $\beta$ & $|t|$ & & $\beta$ & $|t|$ & \\
\hline$p_{11}$ & 0,22 & 11,9 & $\star \star \star ~$ & 0,21 & 10,1 & 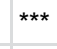 \\
\hline$p_{12}$ & 0 & - & & 0 & - & \\
\hline$p_{21}$ & 0 & - & & 0 & - & \\
\hline$p_{22}$ & 0,78 & 42,5 & *** & 0,79 & 37,8 & *** \\
\hline \multicolumn{7}{|l|}{ All Cancers (1320/7220) } \\
\hline during pregnancy & $-1,63$ & 2,3 & * & & & \\
\hline first life year & & & & $-1,78$ & 2,5 & * \\
\hline$v^{1, c} \quad$ (equal to constant $\left.+v^{2, c}\right)$ & $-1,19$ & 5,5 & 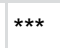 & $-1,21$ & 5,3 & *** \\
\hline (equal to constant) & $-31,00$ & 7,7 & *** & $-31,07$ & 7,8 & *** \\
\hline Baseline hazard parameter $\alpha$ & 0,08 & 18,4 & 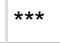 & 0,08 & 18,3 & $\star \star \star ~$ \\
\hline \multicolumn{7}{|l|}{ CVD (2982/7220) } \\
\hline during pregnancy & $-2,05$ & 3,1 & *夫 & & & \\
\hline first life year & & & & $-2,15$ & 3,1 & ** \\
\hline$v^{1, c v d}$ (equal to constant $t^{2, c v d}$ ) & $-3,38$ & 22,2 & **夫 & $-3,34$ & 22,1 & 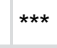 \\
\hline$v^{2, c v d}$ (equal to constant) & $-49,29$ & 9,1 & *** & $-49,22$ & 9,1 & 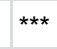 \\
\hline Baseline hazard parameter $\alpha$ & 0,20 & 28,0 & *** & 0,20 & 25,3 & $\star \star \star ~$ \\
\hline
\end{tabular}

Specification 1 only corrects for GDP variations during pregnancy. Specification 2 corrects for GDP variations during first year of life. Fully Adjusted for other macro, socioeconomic and demographic conditions (results not shown). $\dagger<0.1 *<0.05 * *<0.01 * * *<0.001$ 
Table 9 Average residual life expectancies at age 60 for individuals born in 1918 and exposed during pregnancy or during first year of life to different economic condition.

\begin{tabular}{|c|c|c|c|c|c|c|}
\hline \multirow[t]{2}{*}{ During Pregnancy } & \multicolumn{3}{|c|}{ Independent Competing Risk Model } & \multicolumn{3}{|c|}{ Dependent Competing Risk model } \\
\hline & No recession & Average & Maximum & No recession & Average & Maximum \\
\hline GDP value & 0 & $-0,029$ & $-0,187$ & 0 & $-0,029$ & $-0,187$ \\
\hline \multicolumn{7}{|l|}{ Males } \\
\hline Cancer & 23,2 & $23.0(-1.1)$ & $21.5(-7.3)$ & 21,0 & $20.7(-1.2)$ & $19.4(-7.8)$ \\
\hline CVD & 24,3 & $24.2(-0.2)$ & $23.9(-1.5)$ & 17,7 & $17.6(-0.6)$ & $17.0(-4.0)$ \\
\hline \multicolumn{7}{|l|}{ Females } \\
\hline Cancer & 26,3 & $26.1(-0.8)$ & $24.8(-5.5)$ & 27,1 & $26.9(-0.9)$ & $25.5(-6.2)$ \\
\hline CVD & 25,7 & $25.6(-0.6)$ & $24.8(-3.7)$ & 21,8 & $21.7(-0.8)$ & $20.7(-5.4)$ \\
\hline
\end{tabular}

\begin{tabular}{|c|c|c|c|c|c|c|}
\hline \multirow[t]{2}{*}{ During First life year } & \multicolumn{3}{|c|}{ Independent Competing Risk Model } & \multicolumn{3}{|c|}{ Dependent Competing Risk model } \\
\hline & No recession & Average & Maximum & No recession & Average & Maximum \\
\hline GDP value & 0 & $-0,031$ & $-0,187$ & 0 & $-0,031$ & $-0,187$ \\
\hline \multicolumn{7}{|l|}{ Males } \\
\hline Cancer & 23,0 & $22.9(-0.6)$ & $22.2(-3.6)$ & 21,0 & $21.0(-0.4)$ & $20.5(-2.6)$ \\
\hline CVD & 24,4 & $24.3(-0.4)$ & $23.8(-2.5)$ & 18,3 & $18.2(-0.4)$ & $17.9(-2.2)$ \\
\hline \multicolumn{7}{|l|}{ Females } \\
\hline Cancer & 26,8 & $26.5(-1.1)$ & $25.0(-6.9)$ & 27,3 & $27.0(-1.1)$ & $25.5(-6.7)$ \\
\hline CVD & 25,7 & $25.6(-0.6)$ & $24.8(-3.6)$ & 21,9 & $21.7(-0.9)$ & $20.7(-5.7)$ \\
\hline
\end{tabular}

